\title{
Junctional Neurulation: A Unique Developmental Program Shaping a Discrete Region of the Spinal Cord Highly Susceptible to Neural Tube Defects
}

\author{
Alwyn Dady,,$^{1,2}$ Emmanuelle Havis, ${ }^{1,2}$ Virginie Escriou, ${ }^{3}$ Martin Catala, ${ }^{1,2,4}$ and Jean-Loup Duband ${ }^{1,2}$ \\ ${ }^{1}$ Université Pierre et Marie Curie-Paris 6, Laboratoire de Biologie du Développement, 75005 Paris, France, ${ }^{2}$ Centre National de la Recherche Scientifique, \\ Laboratoire de Biologie du Développement, 75005 Paris, France, ${ }^{3}$ Unité de Technologies Chimiques et Biologiques pour la Santé, Centre National de la \\ Recherche Scientifique Unité Mixte de Recherche 8258, Institut National de la Santé et de la Recherche Médicale U1022, Université Paris Descartes, Faculté \\ de Pharmacie, 75006 Paris, France, and ${ }^{4}$ Assistance Publique-Hopitaux de Paris, Federation of Neurology, Groupe Hospitalier Pitié-Salpêtrière, 75013 Paris, \\ France
}

In higher vertebrates, the primordium of the nervous system, the neural tube, is shaped along the rostrocaudal axis through two consecutive, radically different processes referred to as primary and secondary neurulation. Failures in neurulation lead to severe anomalies of the nervous system, called neural tube defects (NTDs), which are among the most common congenital malformations in humans. Mechanisms causing NTDs in humans remain ill-defined. Of particular interest, the thoracolumbar region, which encompasses many NTD cases in the spine, corresponds to the junction between primary and secondary neurulations. Elucidating which developmental processes operate during neurulation in this region is therefore pivotal to unraveling the etiology of NTDs. Here, using the chick embryo as a model, we show that, at the junction, the neural tube is elaborated by a unique developmental program involving concerted movements of elevation and folding combined with local cell ingression and accretion. This process ensures the topological continuity between the primary and secondary neural tubes while supplying all neural progenitors of both the junctional and secondary neural tubes. Because it is distinct from the other neurulation events, we term this phenomenon junctional neurulation. Moreover, the planarcell-polarity member, Prickle-1, is recruited specifically during junctional neurulation and its misexpression within a limited time period suffices to cause anomalies that phenocopy lower spine NTDs in human. Our study thus provides a molecular and cellular basis for understanding the causality of NTD prevalence in humans and ascribes to Prickle-1 a critical role in lower spinal cord formation.

Key words: chick embryo; neural tube defects; neurulation; Prickle-1

\section{Introduction}

Neural tube defects (NTDs) form a very heterogeneous group of severe anomalies affecting the CNS and are among the most common human congenital malformations (De Marco et al., 2006; Copp et al., 2013; Wallingford et al., 2013). Two main phenotypes can be described: in open NTDs, such as spina bifida, the neural tissue is exposed to the surface of the body; whereas in closed NTDs, the impairment lies primarily in its envelopes (TortoriDonati et al., 2000). NTDs may encompass the entire body axis in

\footnotetext{
Received May 7, 2014; revised July 28, 2014; accepted Aug. 19, 2014.

Author contributions: A.D. and J.-L.D. designed research; A.D. and E.H. performed research; V.E. and M.C. contributed unpublished reagents/analytic tools; A.D. and J.-L.D. analyzed data; A.D., M.C., and J.-L.D. wrote the paper.

This work has been performed because of the yearly funding of the Centre National de la Recherche Scientifique and University Pierre and Marie Curie. A.D. was supported by the Ministère de l'Enseignement Supérieur et de la Recherche and the Fondation ARC pour la Recherche contre le Cancer. We thank Thierry Jaffredo, Marie-Aimée Teillet, and Vincent Fleury for advice and discussions; and Tim Sanders, Ken Yamada, and Marie-Emilie Terret for comments on the manuscript.

The authors declare no competing financial interests.

Correspondence should be addressed to either Dr. Jean-Loup Duband or Dr. Alwyn Dady, Laboratoire de Biologie du Développement, Université Pierre et Marie Curie et Centre National de la Recherche Scientifique, 9 quai SaintBernard, 75005 Paris, France, E-mail: jean-loup.duband@upmc.fr or alwyn.dady@gmail.com.

DOI:10.1523/JNEUROSCI.1850-14.2014

Copyright $\odot 2014$ the authors $\quad 0270-6474 / 14 / 3413208-14 \$ 15.00 / 0$
}

some extreme cases called craniorachischisis, but they are mostly found locally and have been categorized as anencephalies in the head or spinal dysraphisms in the trunk. Infants with anencephaly show lack of cranial vaults and cerebral hemisphere and invariably die at birth. Those with spinal dysraphism may survive, albeit enduring severe neurological, urological, and orthopedic disabilities, due to abnormal innervation of the lower trunk.

Although significant progress has been made in the prevention and surgical treatment of NTDs, the etiology of the disease is still obscure because it is a multifactorial pathology. In addition, despite intensive search for NTD-related genes, no one single major gene has emerged as a direct causal agent of the defect in humans (Harris and Juriloff, 2007, 2010). NTDs occur as a result of disturbance in neurulation, the early embryological process shaping the rudiment of the CNS as a hollow tube running along the dorsal midline. In avian and mammalian embryos, neurulation takes place along the axis through two consecutive processes involving radically different morphogenetic events and referred to as primary and secondary neurulations. Primary neural tube forms rostrally by rolling, folding, or bending of the neural plate, a flat epithelial sheet, whereas secondary neural tube is generated caudally by elongation, epithelialization, and cavitation of the tail 
bud, a rod-shaped mesenchyme (Colas and Schoenwolf, 2001; Copp et al., 2003; Saitsu et al., 2004). Classically, open NTDs are attributed to failure of neural tube closure during primary neurulation, whereas closed NTDs concern mostly the lower trunk issued from secondary neurulation. Yet, the exact cellular and molecular events at the origin of NTDs are currently largely unknown. Importantly, the majority of spinal dysraphisms involve the lower spine, at the thoracolumbar and sacral levels (Welch and Winston, 1987). This anatomical region corresponds to the spinal cord situated at the boundary between the portions generated by primary and secondary neurulations (O'Rahilly and Muller, 1994; Saitsu et al., 2004). Specific local morphogenetic events during neurulation have then to be invoked to account for the high incidence of NTDs in this region. Although the existence of a transition zone has been reported in the past (Criley, 1969; Schoenwolf and Delongo, 1980; Lowery and Sive, 2004; Saitsu et al., 2004), little is known about the processes enabling the transition between primary and secondary neurulation so that they assemble into a coherent tubular structure. Here, using the chick embryo model, we show that, at the junction, the neural tube is elaborated by a unique developmental program.

\section{Materials and Methods}

Chick embryos and human fetus. Fertilized hens (Gallus gallus, Brown Leghorn strain) eggs from commercial source (Morizeau) were incubated at $38^{\circ} \mathrm{C}$ until the desired stage determined according to somite numbers and to the Hamburger and Hamilton (1951) (HH) chart. The 18-week human embryo described in this study was collected and analyzed at the Hôpital de la Pitié-Salpêtrière after therapeutic abortion with written permission of the parents, along the guidelines of the French legislation.

DiI-crystal mapping experiments. Fate-mapping studies were performed using DiI microcrystals to label very small groups of cells within the neurectoderm, according to the method designed by Kimura et al. (2006). This technique is noninvasive; no pressure or surgical incision is applied to the surface of the embryo, thereby avoiding any physical damage that might alter cell movements. Embryos were explanted on a filter paper carrier and cultured on a substratum of agar-albumen as described previously (Chapman et al., 2001). Microcrystals of the carbocyanine dye DiI (1,1-dioctadecyl-3,3,3',3' -tetramethyl indocarbocyanine perchlorate; Sigma) were prepared as follows. Briefly, DiI was first dissolved at $0.5 \%(\mathrm{w} / \mathrm{v})$ in absolute ethanol and the solution diluted $1: 1$ in $50 \%$ sucrose in distilled water. A droplet of this solution was deposited from $\sim 30-40 \mathrm{~cm}$ high in a large volume of Pannett-Compton saline, generating a precipitate of DiI crystals of 5-30 $\mu \mathrm{m}$ in diameter. Only crystals of $10-20 \mu \mathrm{m}$ were selected for labeling. After incision of the vitelline membrane, a single or two crystals were placed using a glass micropipette, at defined positions directly on top of the neurectoderm and carefully to avoid injury. The embryos were then incubated at $38^{\circ} \mathrm{C}$ in a moist atmosphere for 3-24 h until the appropriate stage. Images of the labeled embryos were taken immediately after dye deposition and subsequently at regular time points. The positions of the dye crystals were also followed by videomicroscopy under an inverted microscope equipped with a heating chamber. After incubation, some embryos were processed histologically to confirm the position of labeled cells as for immunolocalization studies. Each mapping experiment was performed four times, and videomicroscopy analyses were done in duplicate.

Fluorescent dye cell tracing. CFDA-SE (5-(and-6)-carboxyfluorescein diacetate, succinimidyl ester; Sigma) is a cell-permeant, nonfluorescent dye, which, upon intracellular penetration, is cleaved by the cytoplasmic machinery into a stable, fluorescent product, carboxyfluorescein succinimidyl ester (CFSE). CFSE presents the particularity to bind covalently to intracellular molecules through its succinimidyl group and is thereby retained in the cell cytoplasm and cannot spread to neighboring cells (Wiegreffe et al., 2009). Thus, because it does not permeate through epithelial barrier, this compound may be used to label epithelial cells conveniently and follow their fate reliably. As CFSE cell tracing has not been used frequently in the early chick embryo, we verified that it was not toxic or did not induce malformations in the long term and that it did not penetrate under the superficial layer of the blastoderm at all stages examined. We also defined the optimal concentration and the timing of incorporation of the dye, such as cells, are labeled massively and rapidly, considering that fluorescence intensity must be sufficient to persist at least $24 \mathrm{~h}$ in actively dividing cells and that duration of incorporation must be as short as possible to allow tracing in a rapidly evolving embryo. CFDA-SE was prepared as a $10 \mathrm{~mm}$ stock solution in DMSO and diluted 1:10 in PBS before use. After opening of a window in the egg's shell and incision of the vitelline membrane, CFDA-SE was injected using a glass micropipette directly either over the entire surface of the embryo to label all superficial cells of the blastoderm or focally onto defined regions of the neurectoderm. After injection, embryos were incubated for $1 \mathrm{~h}$ to allow dye penetration and rinsed gently in PBS to remove the dye in excess and prevent it from being further incorporated into cells. Embryos were reincubated for up to $24 \mathrm{~h}$, fixed, sectioned, and processed for immunolocalizations as described below. A minimum of three embryos was analyzed for each stage and for each timing after dye incorporation.

siRNA-based loss-of-function experiments. For loss-of-function experiments, siRNAs were applied to cultured embryos using a modified version of the lipofection protocol designed previously (Bollérot et al., 2006). Three duplex siRNAs (one of which was fluorescein labeled) corresponding to different regions of the Prickle- 1 messengers and the universal siRNA negative control were designed by and purchased from Eurogentec: siRNA.1 cPrikle-1: sense, 5'-GGGCAGAUCUACUGUUCAA (dTdT)-3'; antisense, $3^{\prime}$ - (dTdT) CCCGUCUAGAUGACAAGUU5'; siRNA.2 cPrickle-1: sense, 5'-CAUGGGAACUCUGAAUUCU (dTdT)-3'; antisense, $3^{\prime}$-(dTdT) GUACCCUUGAGACUUAAGA-5'; siRNA.3 cPrickle-1: sense, 5'-GGCAAGCUUUGUUAACGAA (dTdT)3'; antisense, 3' -(dTdT) CCGUUCGAAACAAUUGCUU-5'.

In all cases, BLAST analysis revealed that the siRNAs match specifically to three separate regions along the targeted genes. siRNAs were mixed to lipoplexes composed of a 50\% cationic lipid, RPR209120 (2-\{3-[bis-(3amino-propyl)-amino]-propylamino $-N$-ditetradecylcarbamoylmethylacetamide (United States Patent 6,171,612, January 9, 2001), 45\% of a neutral lipid, dioleyl phosphatidyl ethanolamine (Avantis Polar Lipids), and 5\% rhodamine-conjugated dioleyl phosphatidyl ethanolamine. An equal volume of liposome suspension (at the appropriate concentration) was added to the siRNA-sodium alginate (Sigma) solution $(1 / 1, w / w)$ and vigorously mixed during $1 \mathrm{~min}$ (Schlegel et al., 2011). Typically, $1 \mu \mathrm{g}$ of siRNA and $1 \mu \mathrm{g}$ of sodium alginate were complexed with $10.9 \mathrm{nmol}$ of cationic lipid, in a $150 \mathrm{~mm} \mathrm{NaCl}$ solution. Lipoplexes were allowed to form for $20 \mathrm{~min}$ at room temperature before use. For each embryo, $\sim 10 \mu \mathrm{l}$ of lipoplex solution corresponding to $50 \mathrm{ng}$ of siRNAs was delivered over the surface of the blastoderm, and the embryos were analyzed using the same procedure as for CFSE tracing.

RNA isolation, reverse transcription, and quantitative real-time PCR. To assess the efficiency of siRNAs directed against cPrickle-1, four and 12 HH8 embryos were injected in the node-streak border (NSB) with the universal siRNA negative control and the cPrickle-1 siRNAs, respectively. The posterior region of the embryos of each group were collected and pulled 6 h later, at HH9. Each sample was disrupted by a mechanical disruption device for $40 \mathrm{~s}$ at $6 \mathrm{~m} . \mathrm{s}^{-1}$ (Lysing Matrix A, Fast Prep MP1). Total RNAs were extracted using the RNeasy mini kit (QIAGEN). RNAs were reverse-transcribed using the High Capacity Retrotranscription kit (Applied Biosystems) according to the manufacturer's instructions. Quantitative real-time PCR was performed using SYBR Green PCR Master Mix (Applied Biosystems). RNA quantity was extrapolated from the standard curve by the StepOnePlus Real-time PCR Software (Applied Biosystems). All primers were used at $400 \mathrm{~nm}$. Primer sequences for real-time PCR were as follows: cPrickle-1: forward, 5'-CATAACAGGGGCTTCAATGG-3'; reverse, 5'-AGAGAGATTGCCGTGGCTTT-3'; cGAPDH: forward, 5'-TGGAGAAACCAGCCAAGTATG-3'; reverse, 5' -CATCAAAGGTGGAGGAATGG-3'.

The results were expressed as mRNA levels corrected for GAPDH levels in each sample. Gene expression changes were quantified using the $\delta$ - $\delta$ - $\mathrm{C}_{\mathrm{T}}$ method. The experiment was performed three times, and the PCR was performed in duplicate. The fold changes between control and 
siRNA cPrickle-1-injected embryos were assessed for statistical significance by Student's $t$ test.

Immunolocalizations on embryo sections. The following antibodies were used for immunolabelings: the mouse monoclonal antibodies to chick N-cadherin (mAbs FA5 and GC4, 1/1000) were purchased from Sigma; the mAb to mouse E-cadherin (clone 36/E-cadherin, 1/1000) cross-reacting with chick E-cadherin was from BD Transduction Laboratories; a rabbit polyclonal antibody to chick fibronectin (1/1000) described previously (Rovasio et al., 1983) and a rabbit polyclonal antibody to human Sox-2 (1/200) were from Abcam. Embryos were fixed in a 1\% PFA solution in PBS supplemented with $4 \%$ sucrose and $0.1 \mathrm{~mm} \mathrm{CaCl}_{2}$ for $2 \mathrm{~h}$ at room temperature, embedded first in a $15 \%$ sucrose solution, then in a $15 \%$ sucrose $7.5 \%$ gelatin solution, and frozen in chilled isopentane. Sections were cut at $10 \mu \mathrm{m}$ on a cryostat, collected, permeabilized with $0.1 \%$ Triton X-100 in PBS, subjected to immunofluorescence labeling using appropriate secondary antibodies conjugated to AlexaFluor- 488 or -555 (Invitrogen), diluted $1 / 200$, and processed before mounting for DAPI staining. Preparations were observed with an fluorescence microscope, and data were collected using the QCapture Pro software (QImaging) and processed using Adobe Photoshop software. Data were acquired using equal exposure times.

In situ hybridizations to whole-mount embryos and to embryo sections. Plasmids for mRNA probe synthesis for Flamingo, Prickle, and Vangl-2 were obtained from C. Stern, Sox-2 from P. Scotting, Snail-2 from A. Nieto and Bmp-4 from I. Palmeirim. Linearized DNA was used to synthesize digoxigenin-UTP (Roche) labeled antisense probes with RNA polymerases from Promega and RNA probes were purified with Illustra ProbeQuant G-50 microcolumns (GE Healthcare). For in situ hybridizations on sections, embryos were fixed and processed for sectioning as for immunolabelings, except that sections were cut at $20 \mu \mathrm{m}$. Sections were hybridized for $15 \mathrm{~h}$ at $65^{\circ} \mathrm{C}$ with the digoxygenin-UTP-labeled RNA probes in $50 \%$ formamide, $10 \%$ dextran sulfate, and Denhart's buffer $(10$ $\mu \mathrm{l}$ probe at $0.5-1 \mathrm{mg} / \mathrm{ml}$ for $1 \mathrm{ml}$ hybridization buffer and $500 \mu \mathrm{l} \mathrm{buffer/}$ slide). Sections were washed twice during $30 \mathrm{~min}$ in $50 \%$ formamide, $1 \times$ SSC and $0.1 \%$ Tween 20 at $65^{\circ} \mathrm{C}$, then 4 times during $20 \mathrm{~min}$ at room temperature in $100 \mathrm{~mm}$ maleic acid, $150 \mathrm{~mm} \mathrm{NaCl}, \mathrm{pH} 7.5$, and $0.1 \%$ Tween 20 (MABT buffer). After a preincubation of $1 \mathrm{~h}$ in MABT buffer containing 10\% blocking reagent (Roche) and 10\% heat-inactivated lamb serum, sections were incubated overnight at room temperature with the anti-digoxygenin antibody (Roche) diluted 1/2000. After several rinsings with the MABT buffer, the sections were rinsed in $100 \mathrm{~mm} \mathrm{NaCl}$, $50 \mathrm{~mm} \mathrm{MgCl}, 1 \%$ Tween 20, and $25 \mathrm{~mm}$ Tris- $\mathrm{HCl}, \mathrm{pH} 9.5$, and stained with NBT-BCIP (Roche) following the manufacturer's guidelines. Essentially the same procedure was used for the in situ hybridizations on whole-mount embryos. Preparations were observed with a microscope for embryo sections and a stereomicroscope for whole-mount embryos, and data were collected using the QCapture Pro software (QImaging) and processed using Adobe Photoshop software. In situ hybridizations were systematically done in triplicate for each developmental stage.

\section{Results}

To gain insight into the mechanism involved in the morphogenetic continuity between the primary and the secondary neurulation processes, we made use of the chick embryo as an experimental system. Indeed, neurulation has been best studied in this species because of the accessibility of the embryo to in vivo manipulations throughout development (Colas and Schoenwolf, 2001). Contrary to the mouse and other tailed animals in which only the tail is formed by secondary neurulation, in chick, the anatomical region in which the spinal cord is shaped by secondary neurulation extends up to the lumbar region and matches more closely that in human, apart from the fact that in the latter, the spinal cord does not extend to the spine end due to discordance between growth of neural and mesodermal tissues during fetal life (Fig. 1A) (Criley, 1969; Schoenwolf and Delongo, 1980; Schoenwolf, 1984; Nievelstein et al., 1993; O'Rahilly and Muller, 1994; Catala et al., 1995; Colas and Schoenwolf, 2001; O’Rahilly and Muller, 2003; Saitsu et al., 2004; Shum et al., 2010). In addition, whereas a junctional region in which primary neurulation overlaps dorsally with secondary neurulation ventrally has been reported in chick and human, no such transition zone has been described in mouse (Criley, 1969; Schoenwolf and Delongo, 1980; Schoenwolf, 1984; Saitsu et al., 2004). Finally, NTDs can be induced experimentally in the lower spine at high incidence in chick, thereby mimicking the human situation, whereas in mouse their frequency is extremely low (Hughes and Freeman, 1974; Schoenwolf, 1979; Saitsu et al., 2004).

\section{The junctional region derives from a discrete region in the node-streak border}

Closure of the caudal neuropore and beginning of extension of the tail bud are considered to mark the end of primary neurulation and onset of secondary neurulation. In chick, these events take place at $\mathrm{HH} 12$, corresponding to $\sim 18-22$-somite embryos at $48 \mathrm{~h}$ of incubation. However, fate-mapping studies established that all the material forming the caudal neural tube below the upper thoracic level up to the extremity of the tail is generated precociously in a discrete region of the neural plate situated in between the Hensen's node and the primitive streak (Catala et al., 1996; Shimokita and Takahashi, 2011). This region, referred to as $\mathrm{NSB}$, is a transient structure that becomes discernible at $\mathrm{HH} 8$ (6-somite stage) and gradually shrinks until it disappears at caudal neuropore closure. Therefore, cells that contribute the junctional neural tube are presumably issued from this region in the intervening time between $\mathrm{HH} 8$ and $\mathrm{HH} 12$.

Using histological, cell tracing, and videomicroscopic approaches, we investigated the molecular and cellular characteristics of the NSB and analyzed the mechanisms underlying its morphogenetic transformation into a neural tube. At $\mathrm{HH} 8$, the NSB displayed neural folds laterally in continuity with the primary neural plate as well as remnants of the primitive streak medially. During node regression and axis elongation, its overall shape evolved from wide and flat to cup-shaped at HH9 and ultimately tubular at HH10-11 (Fig. 1 B, C). Most strikingly, contrary to primary neurulation, movements of neurulation occurred in the NSB before formation of the notochord, and it was only during the ultimate steps of neural tube closure that notochordal progenitors became arranged in a solid cord after regression of the node (Fig. 1C). Analysis of the spatial distribution of neural progenitors using Sox- 2 as an early neural marker revealed that, in the primary neural tube, the neural plate was composed of a uniform population of neural progenitors expressing Sox-2 from the early steps of neurulation and that this spatial organization remained unaltered throughout the movements of fold elevation and tube closure (see Fig. $4 A$ ). In the NSB, in contrast, the superficial layer was composed at $\mathrm{HH} 8$ of two distinct populations: Sox-2-positive cells distributed as lateral stripes in continuity with the primary neural tube; and Sox-2-negative cells along the midline in continuity with the streak (Fig. 1D). As neurulation proceeded, Sox-2 expression expanded medially, suggesting that, in the midline, cells were progressively undergoing neural differentiation. Tracking of DiI microcrystal marks at HH8HH12 showed that these cell populations executed separate movements during neural tube closure. Indeed, whereas marks deposited laterally on the folds at $\mathrm{HH} 8$ were displaced medially, consecutive to movements of fold elevation as observed during primary neurulation, marks placed in the midline moved caudalward along the rostocaudal axis during node regression, instead of moving in synchrony with lateral marks until getting superimposed to them as seen in regions of primary neurulation (Fig. 1E). 
A

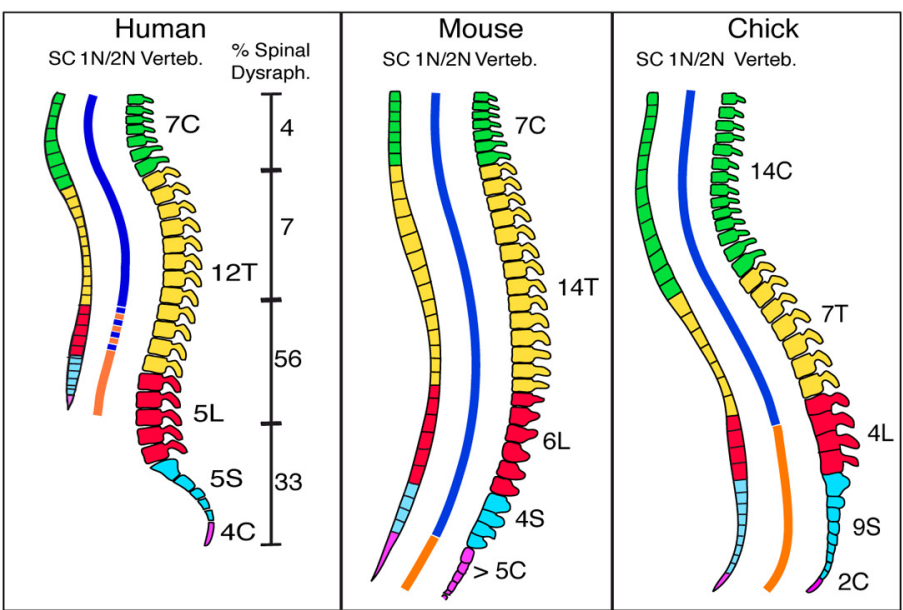

B

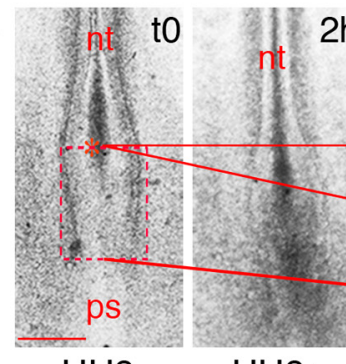

$\mathrm{HH} 8$

D

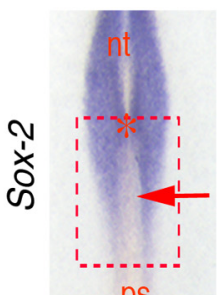

ps

HH8+

$\mathrm{HH} 9$

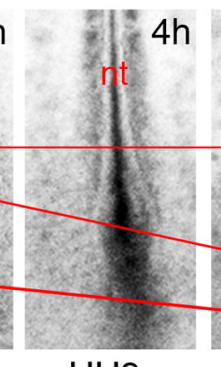

(2)

$\mathrm{HH} 10$

$\mathrm{HH} 8$

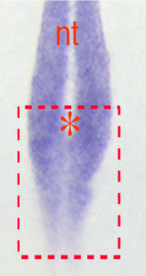

ps

$\mathrm{HH} 9$

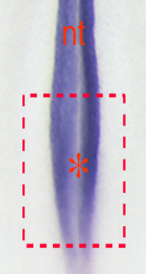

ps

$\mathrm{HH} 10$

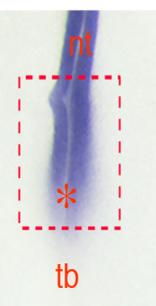

$\mathrm{HH} 12$
$8 h$

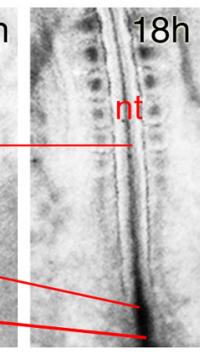

$\mathrm{HH} 12$
C
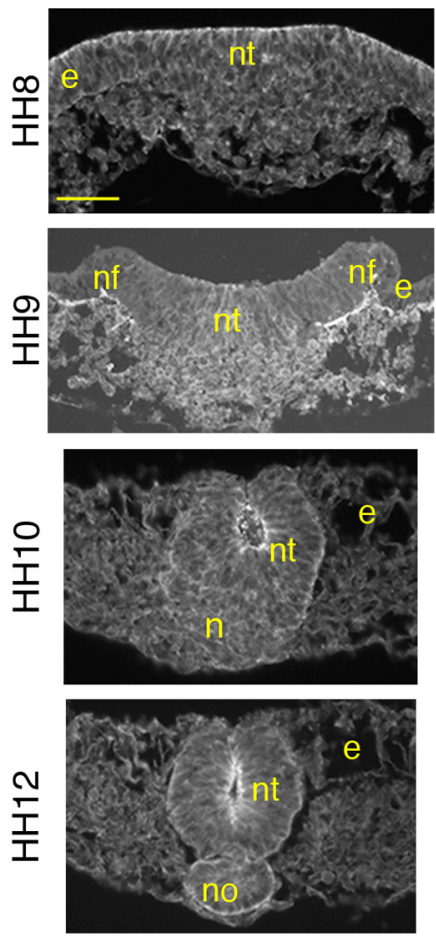

F-actin
E

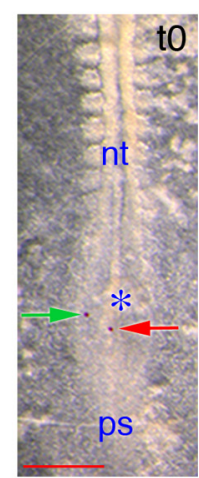

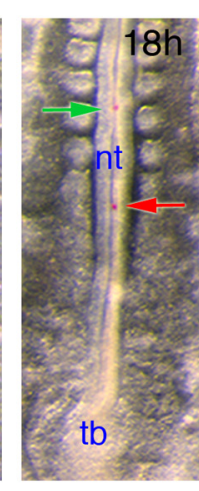

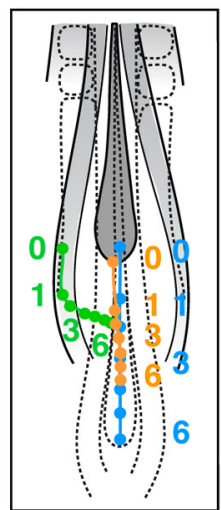

Figure 1. Topological and cellular characterization of the NSB. $A$, Schematic representations of the spine in human, mouse, and chick, depicting the topological correspondence between the different categories of vertebrae (C, cervical; $T$, thoracic; L, lumbar; S, sacral; and C, caudal), the spinal cord (SC) and the regions of primary and secondary neurulations (1N/2N; blue and orange lines, respectively). The border between primary and secondary neurulations was defined by the position of the closure of the posterior neuropore, in mouse after the last sacral vertebra (somite level 36) and in chick after the second lumbar vertebra (somite level 28) (Criley, 1969; Hughes and Freeman, 1974; Schoenwolf, 1979, 1984; Schoenwolf and Delongo, 1980; Catala et al., 1995; Catala et al., 1996; Colas and Schoenwolf, 2001; Shum et al., 2010). In human, the exact position of the border is still debated (hence has been represented by dotted lines) because the spinal cord does not extend to the spine end (Nievelstein et al., 1993; 0'Rahilly and Muller, 1994; Saitsu et al., 2004). The prevalence of spinal dysraphisms along the axis (expressed as percentage of total cases at birth) was based on the meta-analysis by Welch and Winston (1987). B, Time-lapse images of the NSB of a chick embryo at HH8-HH12, viewed dorsally by phase-contrast microscopy. Image capture started at $\mathrm{HH} 8$ and finished $18 \mathrm{~h}$ later at HH12. Red bars represent the caudal regression of the node and axis elongation of the embryo. The red, dotted square and the asterisk indicate the initial positions at HH8 of the NSB and node, respectively. nt, Neural tube; ps, primitive streak. Scale bar, $200 \mu \mathrm{m}$. C, Cross-sections through the NSB at HH8-HH11, stained for rhodamine-conjugated phalloidin, showing changes in tissue morphology during movements of neurulation. Contrary to primary neurulation, notochord forms ultimately after completion of neurulation. e, Ectoderm; $n$, Hensen's node; nf, neural fold; no, notochord; nt, neural tissue. Scale bar, $50 \mu \mathrm{m}$. D, Whole-mount in situ hybridizations for Sox-2 showing the NSB at HH8-HH12. The red, dotted squares indicate the initial position of the NSB at HH8; asterisks indicate the positions of the node; the arrow points to the Sox-2-negative cells in the midline at HH8. nt, Neural tube; ps, primitive streak; tb, tail bud. Scale bar, $100 \mu \mathrm{m}$. E, Superficial cell movements traced using Dil microcrystals. Left panels, Phase-contrast images of the caudal region of a chick embryo, viewed dorsally, immediately after deposition of two Dil microcrystals (indicated by green and red arrows) and $18 \mathrm{~h}$ later. Asterisk indicates node position. Right panel, Schematic representation of NSB showing the trajectories of two Dil microcrystals deposited at HH8 laterally (green) and medially (orange) over the embryo and their positions every hour in relation to regression of the node (blue). The shapes and relative positions of tissues after $6 \mathrm{~h}$ are indicated by dotted lines. nt, Neural tube; ps, primitive streak; tb, tail bud. Scale bar, $200 \mu \mathrm{m}$.

These observations therefore indicate that the NSB constitutes a discrete region in continuity with the primary neural tube but characterized by specific topological features and distinct morphogenetic transformations.

Although the rostral limit of the secondary neural tube has been mapped with precision to the level of the $27-28$ th pairs of somites (Catala et al., 1996; Shimokita and Takahashi, 2011), the portion of the anatomical region of the spine corresponding to the junctional region and generated in the NSB is not known precisely. To do this, we determined the final position along the rostrocaudal axis of DiI microcrystal marks deposited at the level of the node at intervening stages during transition from primary 

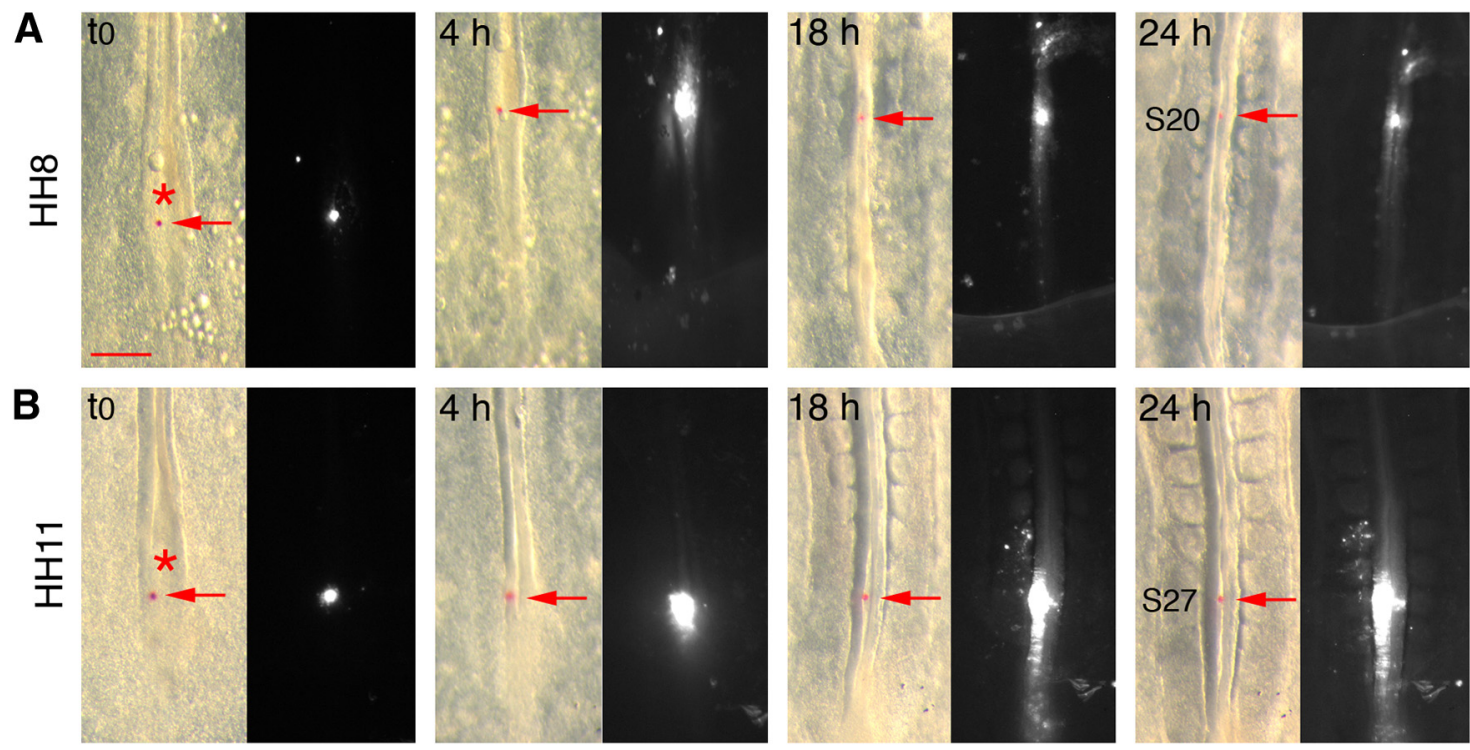

\section{C}
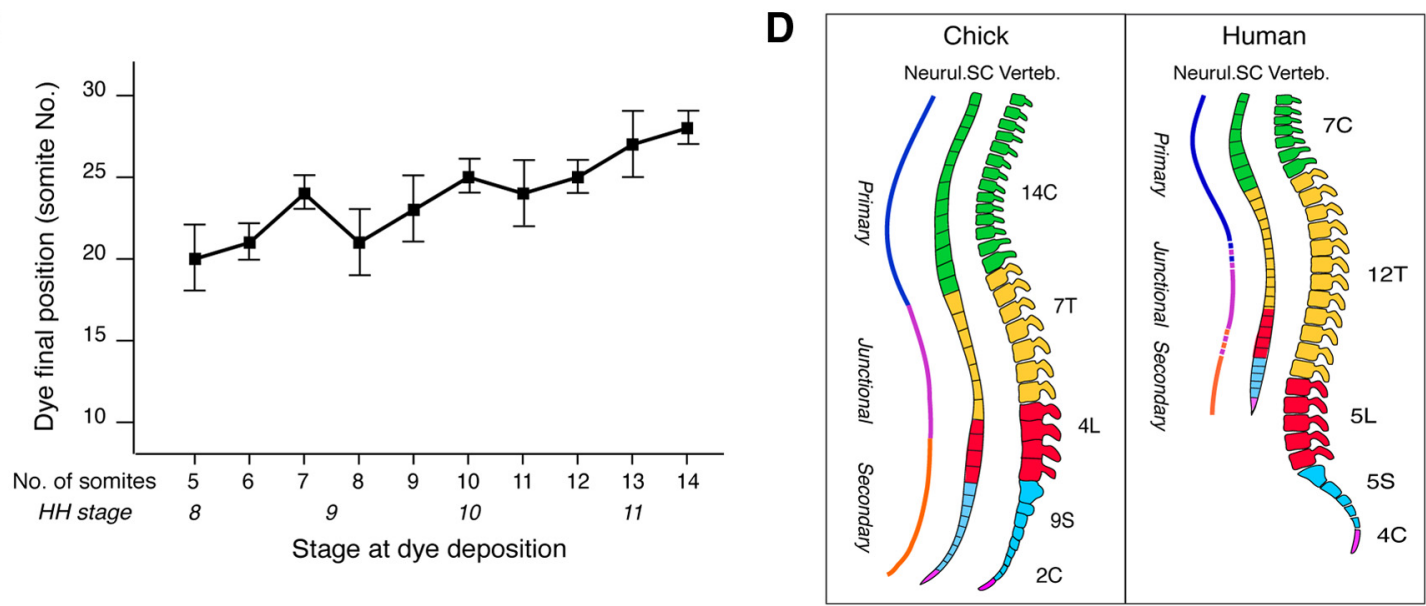

Figure 2. Dil microcrystal mapping of the spinal cord generated at the NSB. $A, B$, Bright-field and fluorescence views of the caudal region of embryos marked with Dil microcrystals (indicated by arrows) at HH8 ( $\boldsymbol{A})$ and $\mathrm{HH} 11(\boldsymbol{B})$, and examined 4,18 , and $24 \mathrm{~h}$ later. The position of the crystal along the rostrocaudal axis after $24 \mathrm{~h}$ is defined relative to somite (S) pairs. $\boldsymbol{B}$, Fluorescent neural tube cells are found after $24 \mathrm{~h}$ over several somites long because of active proliferation combined with rapid axis elongation of the embryo. Asterisks indicate the positions of the node at $\mathrm{t} 0$. Scale bar, 200 $\mu \mathrm{m}$. C, Diagram showing the final position of crystals relative to somite numbers ( \pm SD), plotted as a function of the developmental stage of labeling given in number of somites and in $H H$ stages ( $n=4$ for each point). $D$, Extrapolation of the position in chick and human of the spinal cord generated from the NSB, based on the fact that in chick the thoracic region corresponds to somite pairs 19-26. Blue line indicates primary neural tube; orange line indicates secondary neural tube; purple line indicates junctional region.

to secondary neurulation. Marks placed at $\mathrm{HH} 8$ were invariably found later at the level of the 18-20th somite pairs, whereas those placed at late HH11 were found, as expected, at the level of the 27-28th pairs (Fig. $2 A-C$ ). These data reveal that the junctional region encompasses the entire thoracic region in chick, corresponding approximately to the thoracolumbar region in human (Fig. 2D).

\section{The junctional neural tube is elaborated by a specific developmental program}

To define the cellular movements occurring in the NSB, we traced cells of the superficial layer of the blastoderm using CFSE, a cellpermeant fluorescent dye unable to cross epithelial barriers (Wiegreffe et al., 2009). When dye application was performed in the primitive streak region during gastrulation at $\mathrm{HH} 4(n=4)$, labeled cells were seen within $3 \mathrm{~h}$ ingressing massively in the underlying space and moving laterally; and after $18 \mathrm{~h}$, they were distributed evenly in all three primary germ layers (Fig. $3 A$ ). When applied over the primary neural tube at HH6-7 $(n=7)$, CFSE was found later in the entire neural tube, consistent with the fact that throughout neurulation all neural progenitors remained in contact with the exterior up to completion of neural tube closure (Fig. 3B). Conversely, if labeling was performed over the tail bud at onset of secondary neurulation at HH12 $(n=24)$, no neural tube cells exhibited staining, indicating that at this stage, all neural progenitors of the secondary neural tube were covered by the ectoderm and located deeply in the tail bud (Fig. $3 E)$. When CFSE was applied over the NSB at HH8 $-9(n=23)$, the junctional neural tube consisted entirely of labeled cells $18 \mathrm{~h}$ later as observed during primary neurulation, indicating that it was derived exclusively from progenitors situated superficially (Fig. 3C). However, examination of embryos 3-6 h after labeling revealed the presence of labeled cells scattered medially underneath the superficial layer. Interestingly, when dye was applied at HH10 $(n=32)$, only a few labeled cells were visualized ventrally after $3 \mathrm{~h}$; and after $18 \mathrm{~h}$, the neural tube contained labeled cells dorsally and nonlabeled cells ventrally, separated by a mixed population (Fig. 3D). These observations indicate that, by the time of dye application, cells forming the ventral neural tube were situated beneath the superficial layer and inaccessible to the dye. A 

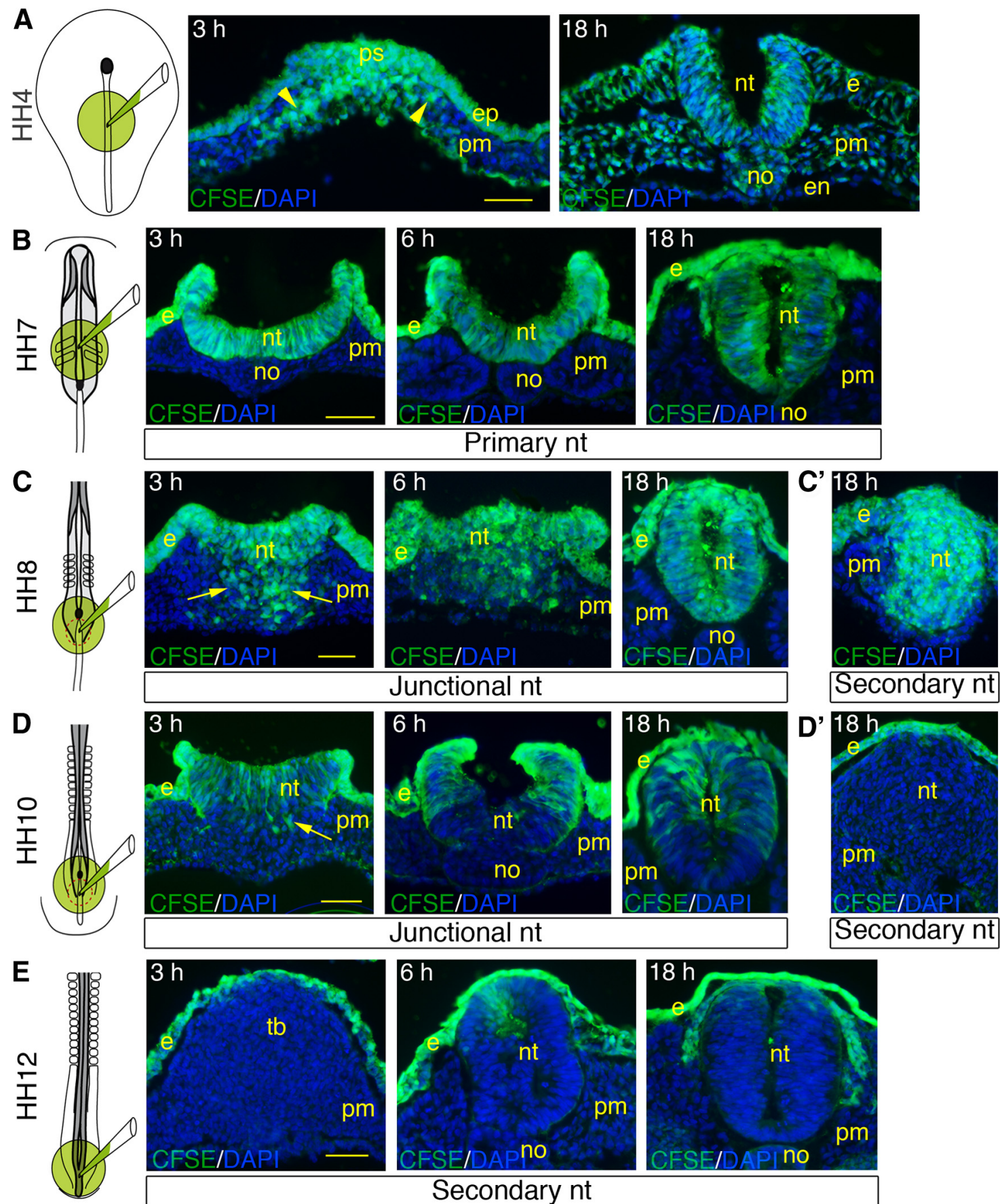

Figure 3. CFSE tracing of neural progenitors in the NSB. CFSE and DAPI visualization on cross-sections through chick embryos labeled with CFSE at the level of the primitive streak at HH 4 ( $A$ ), the primary neural tube at $\mathrm{HH7}(\boldsymbol{B})$, the NSB at $\mathrm{HH} 8(\boldsymbol{C})$ and $\mathrm{HH} 10(\boldsymbol{D})$, and the secondary neural tube at $\mathrm{HH} 12(\boldsymbol{E})$. Embryos were labeled for1 $\mathrm{h}$, rinsed, and further incubated during 3, 6, and $18 \mathrm{~h}$ before analysis. Far left panels, Embryonic area where the dye was applied. $\boldsymbol{A}$, Sections through the primitive streak (left) and the anterior trunk (right). $\boldsymbol{B}$, Sections though the primary neural tube. $\boldsymbol{C}, \boldsymbol{D}$, Sections through the mid-portion of the NSB (left and middle) and the junctional neural tube (right). $\boldsymbol{C}^{\prime}, \boldsymbol{D}^{\prime}, \boldsymbol{E}$, Sections through the secondary neural tube. Arrowheads point at fluorescent cells ingressing in the primitive streak and migrating laterally; arrows point to fluorescent cells dispersed in the space underneath the superficial layer at the level of the NSB. e, Ectoderm; en, endoderm; ep, epiblast; no, notochord; nt, neural tissue; pm; paraxial mesoderm; ps, primitive streak; tb, tail bud. Scale bar, $50 \mu \mathrm{m}$.

plausible explanation is that a number of cells initially situated superficially in the NSB were released in the underlying space between $\mathrm{HH} 8$ and HH10 by a process related to epithelium-tomesenchyme transition (EMT) and subsequently integrated into the forming neural tube.

We therefore investigated the expression patterns of adhesion molecules and EMT regulatory factors throughout the course of neurulation in the NSB in comparison with the primary neural tube. During primary neurulation, the entire neural plate re- mained as an intact epithelium throughout the process of rolling and fold elevation, apposition, and fusion. None of the molecular and cellular signs of cells normally undergoing EMT (Thiery and Sleeman, 2006) was detected in any portion of the neural plate: Snail-2 and Bmp-4 were virtually absent from neural epithelial cells and were only found in the prospective neural crest cells at the interface with the ectoderm (Fig. 4A), and there was no breakdown of the basement membrane accompanied by a rapid switch from E-cadherin to $\mathrm{N}$-cadherin (Fig. 4B,C), as seen, for example, 
A
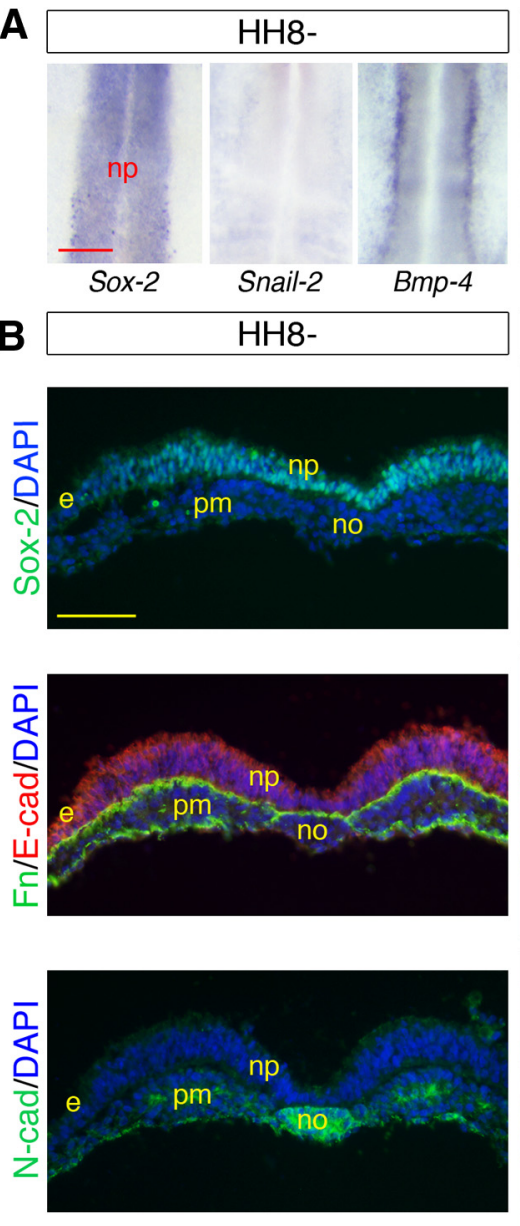

C

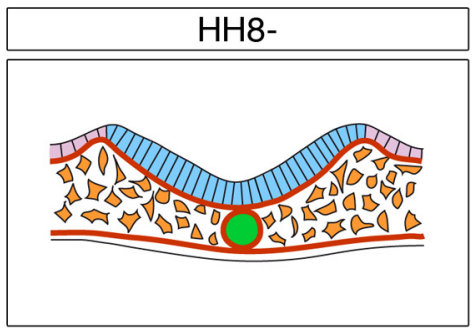

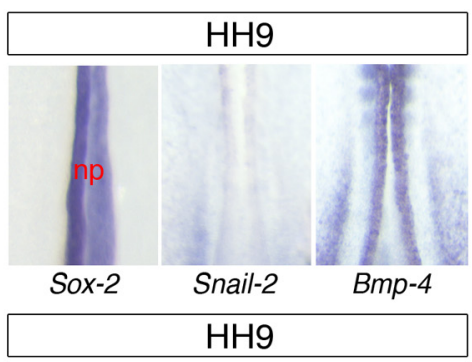
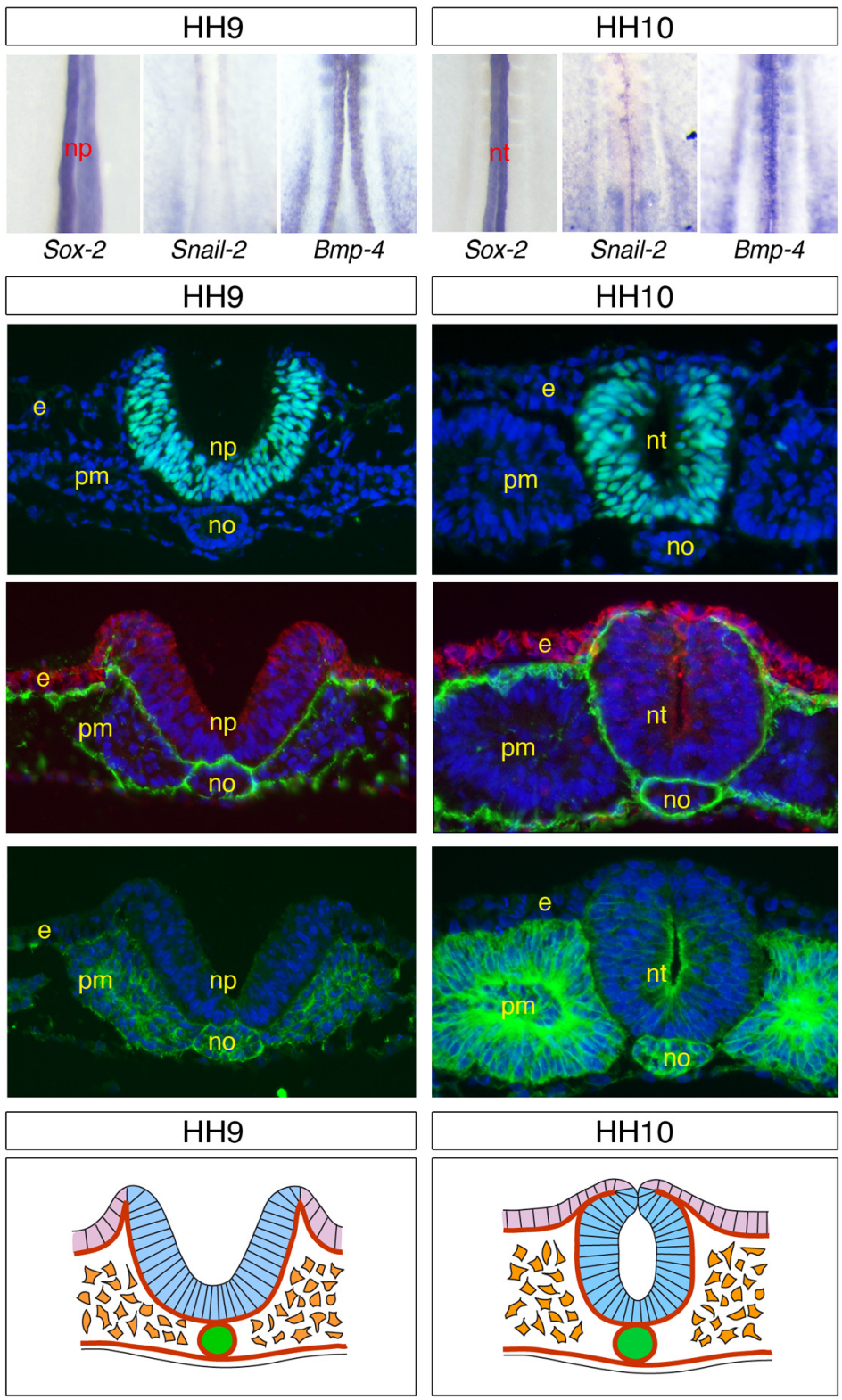

Figure 4. Molecular and cellular characterization of the neural cells contributing to the primary neural tube. $A$, Whole-mount in situ hybridizations for Sox-2, Snail-2, and Bmp-4, showing the anterior trunk from embryos from $\mathrm{HH} 8$ to $\mathrm{HH} 10$ during primary neurulation. Throughout the process of elevation of the neural folds and neural tube closure, the neural plate is constituted entirely by Sox-2-positive cells and Snail-2 and Bmp-4 are confined to prospective neural crest cells first laterally and then dorsally at neural tube closure. np, Neural plate; nt, neural tube. Scale bar, $100 \mu \mathrm{m}$. B, Immunostainings for Sox-2, fibronectin, E-cadherin, and N-cadherin and DAPI visualization on cross-sections through the anterior trunk from HH8 to HH10. e, Ectoderm; no, notochord; np, neural plate; nt, neural tube; pm, paraxial mesoderm. Scale bar, $50 \mu \mathrm{m}$. C, Schematic representations of cross-sections through the anterior trunk at HH8-HH10, illustrating the movements of elevation of the neural folds and neural tube closure during formation of the primary neural tube. The neural epithelium remains as an intact epithelium throughout the folding process until neural tube closure. Light blue represents Sox-2-positive neural cells; light purple represents ectoderm; green represents notochord; orange represents paraxial mesoderm; thick brown lines indicate basement membranes.

in the primitive streak during gastrulation (Nakaya et al., 2004; Dady et al., 2012). In the junctional region, only Sox-2-positive cells situated in either side of the NSB exhibited characteristics of primary neural tube cells: they were organized as an epithelium expressing E-cadherin and limited by a continuous basement membrane. These cells ultimately contributed to the dorsal neural tube and underwent few major molecular changes, except a gradual E- to N-cadherin expression switch (Fig. 5A-C). Sox-2-negative cells situated medially, in contrast, shared a number of features with mesodermal progenitors in the streak (Nakaya et al., 2004; Dady et al., 2012): initially, at HH8, they were devoid of a basement membrane and expressed Snail-2,
Bmp-4, and N-cadherin instead of E-cadherin, all features of cells undergoing EMT (Thiery and Sleeman, 2006) (Fig. 5AC). However, unlike mesodermal precursors (Fig. $3 A$ ), they did not disperse laterally once delaminated at $\mathrm{HH}$, and they did not contribute to the paraxial mesoderm, as shown by the absence of CFSE-labeled cells in non-neural tissues (Fig. $3 C, D)$. Instead, these cells started expressing Sox-2 and mingled with the dorsolateral neural epithelial cells by a process reminiscent of cell intercalation, followed by cell epithelialization and deposition of a basement membrane (Fig. 5A-C). Importantly, Sox-2-negative cells undergoing EMT not only contributed to the ventral neural tube in the junctional region 
A

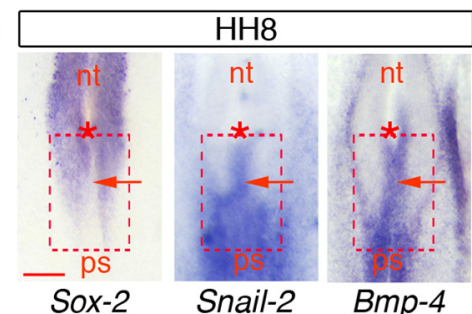

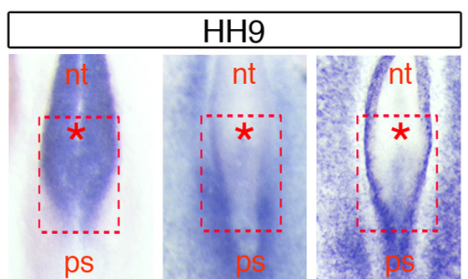

Sox-2

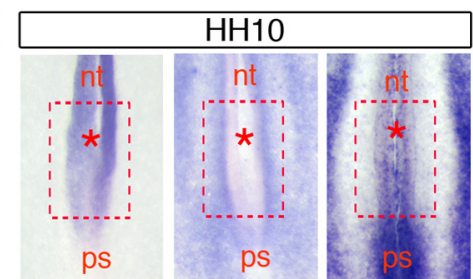

Sox-2

Snail-2
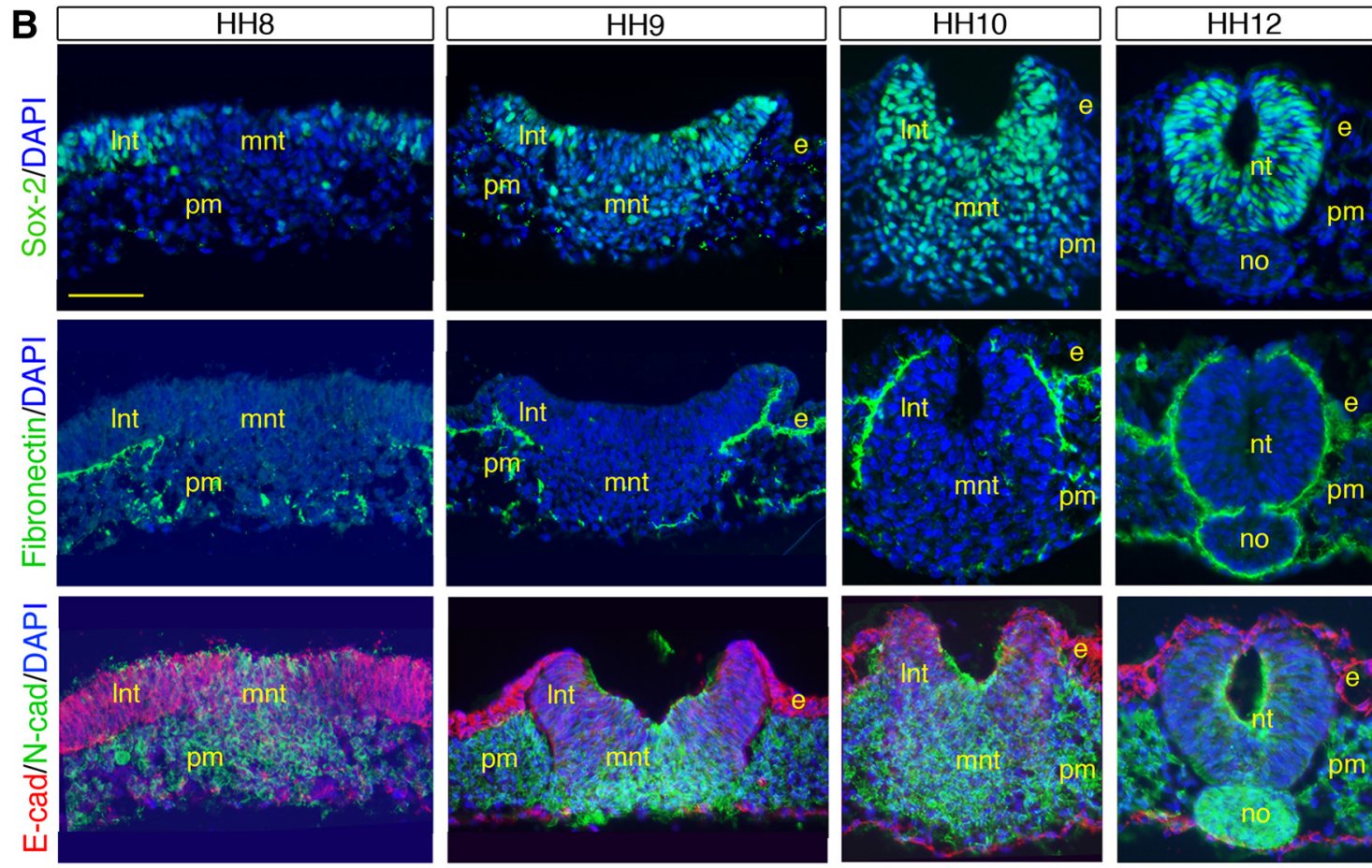

C
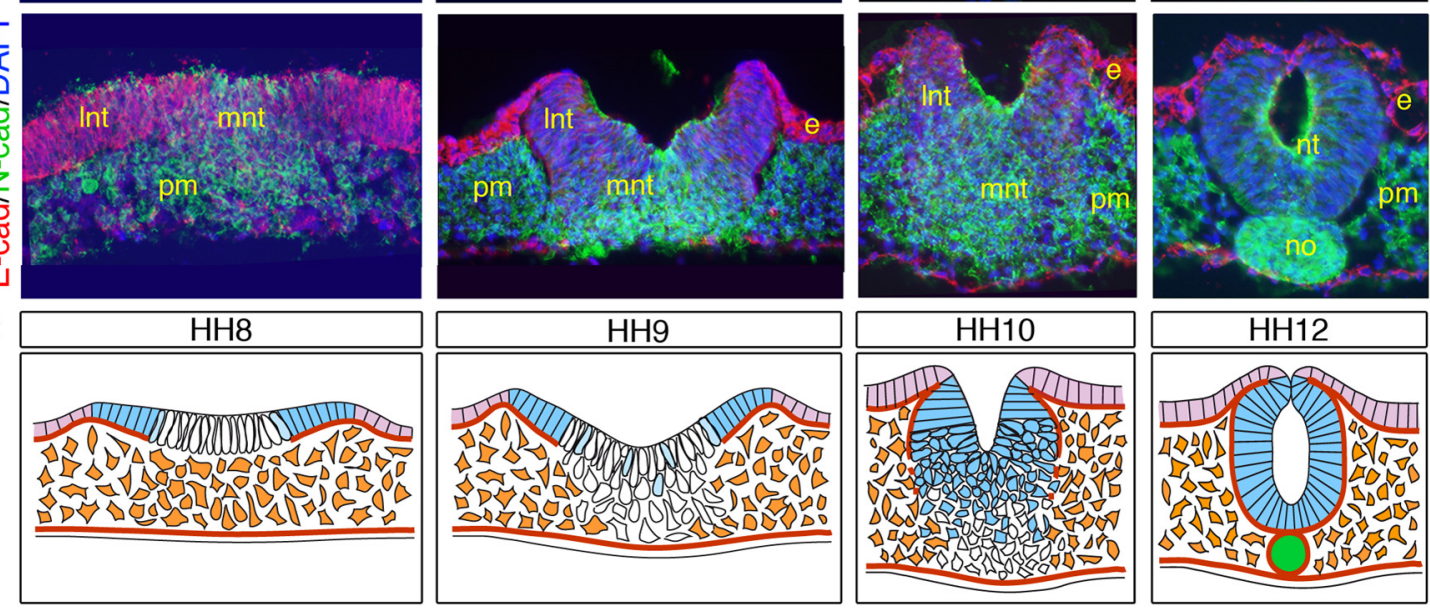

Figure 5. Molecular and cellular characterization of the cell populations in the NSB.A, Whole-mount in situ hybridizations for Sox-2, Snail-2, and Bmp-4 from HH8 to HH10, revealing the existence at HH8 of two distinct cell populations differing by their mutually exclusive Sox-2 and Snail-2/Bmp-4 expressions. Red, dashed square represents the position of the NSB at HH8. Asterisks indicate the node positions; arrows point to the Sox-2-negative, Snail-2/Bmp-4-positive cells medially. nt, Neural tube; ps, primitive streak. Scale bar, $100 \mu \mathrm{m} . \boldsymbol{B}$, Immunostainings for Sox-2, fibronectin, E-cadherin, and N-cadherin on cross-sections through the NSB at HH8-HH12. e, Ectoderm; no, notochord; Int and mnt, lateral and medial neural tissues; pm, paraxial mesoderm. Scale bar, $50 \mu \mathrm{m}$. C, Schematic representations of cross-sections through the NSB at HH8-HH12, reconstituting movements of cell populations during formation of the junctional neural tube. Light blue represents Sox-2-positive neural cells; white represents Sox-2-negative neural progenitors; light purple represents ectoderm; green represents notochord; orange represents paraxial mesoderm; thick brown lines indicate basement membranes. At HH8, the superficial layer of the NSB is constituted of two adjacent cell populations: One is situated laterally and contains Sox-2-positive cells that express E-cadherin and are limited by a basement membrane. The other population located medially contains Sox-2-negative cells that are not limited by a basement membrane and are undergoing an Eto $\mathrm{N}$-cadherin switch. From HH9 to HH12, lateral cells undergo elevation and folding to become gradually displaced dorsally as during primary neurulation. In contrast, cells located medially lose their epithelial organization and accumulate beneath to form a mass of compact cells that progressively express Sox-2. These cells later reorganize as an epithelium in continuity with the dorsal neural tube and become limited by a basement membrane extending dorsoventrally.

but also were the source of cells for the caudal neural tube generated by secondary neurulation, as evidenced by the integral CFSE labeling of the caudal neural tube when dye was applied at $\mathrm{HH} 8$ and before HH10 (Fig. $3 C^{\prime}, D^{\prime}$ ). Thus, contrary to the primary neural tube, which forms from a uniform sheet of neural progenitors all participating to the movements of rolling and folding (Fig. 4C), the neural tube in the junctional region forms from two adjacent populations initially situated superficially but executing distinct morphogenetic programs before they assemble into a coherent neural tube (Fig. 5C).

We next analyzed how these cell populations are distributed spatially along the rostrocaudal axis to allow the continuity between the primary and secondary neural tubes. Cell tracing after short pulses of CFSE labeling combined with immunohistology for cell lineage markers and adhesion molecules revealed that, at $\mathrm{HH}$, cells undergoing EMT were limited to a narrow band in the midline in the rostral NSB, whereas they extended up to the lat- 
A
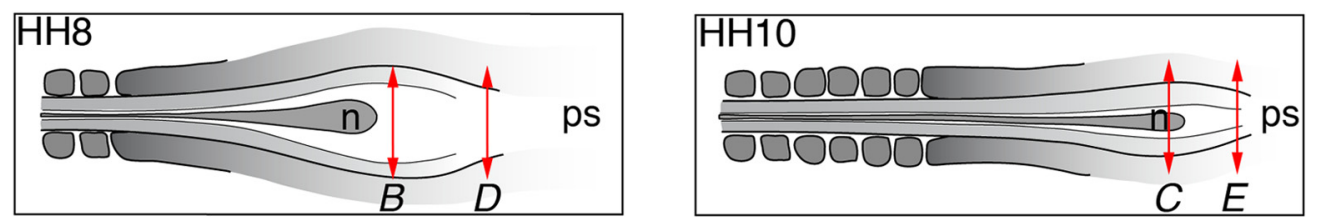

B
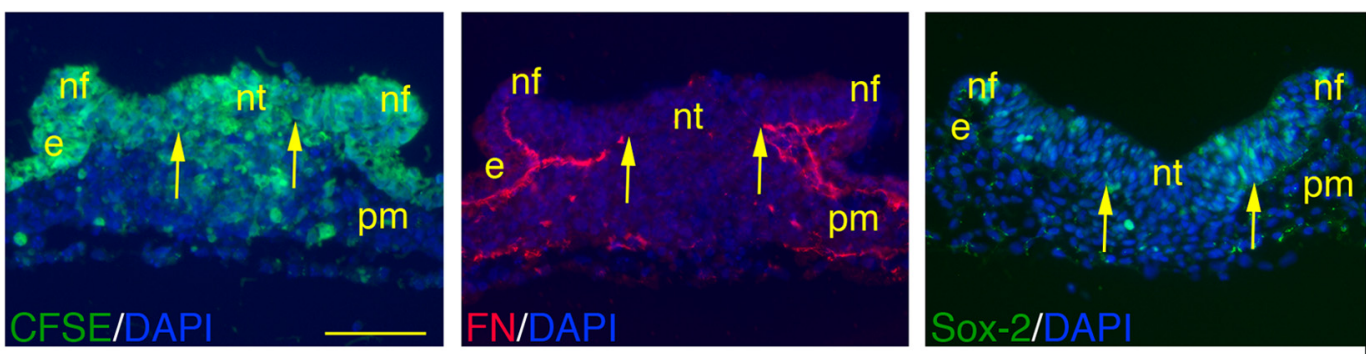

$\mathbf{C}$
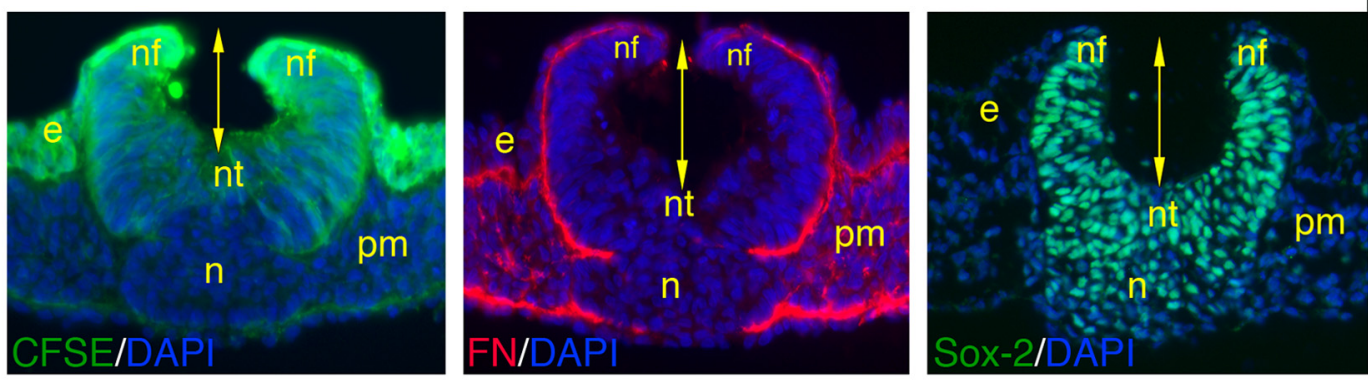

D
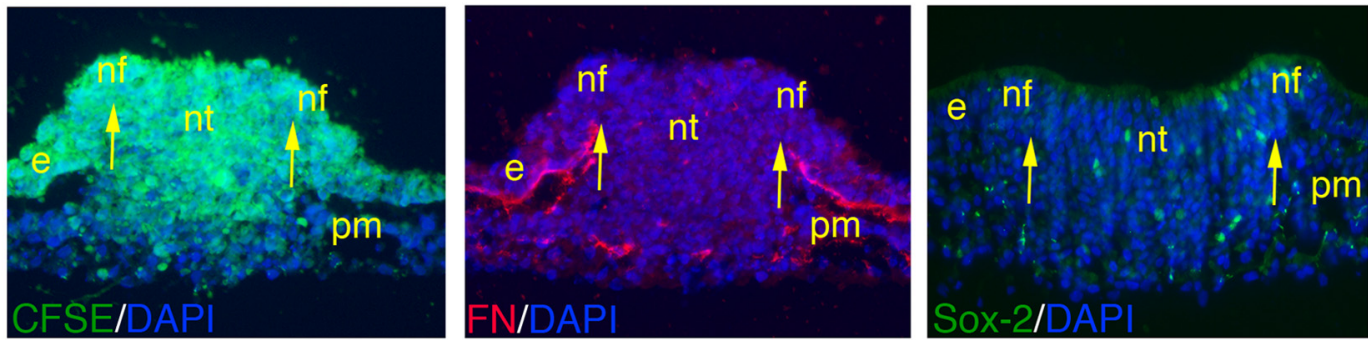

E
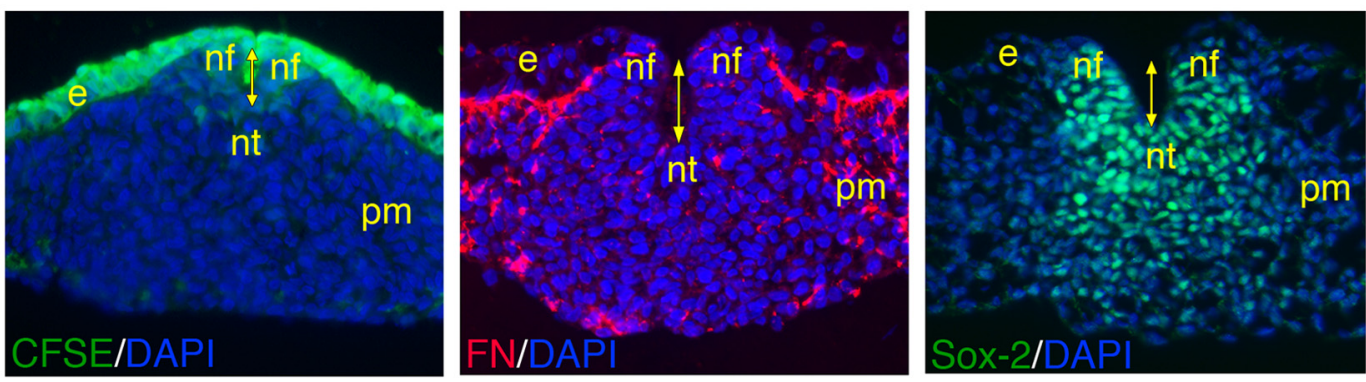

$\mathbf{F}$

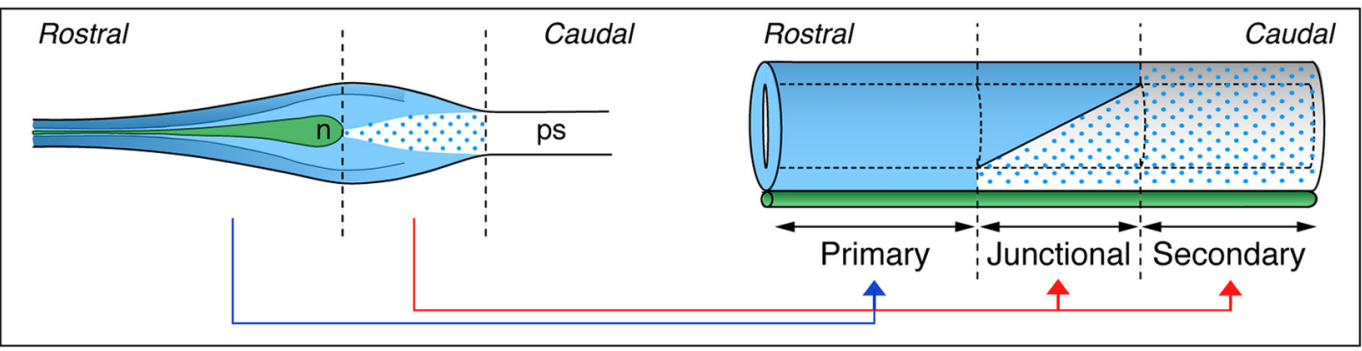

Figure 6. Topological continuity between the primary and secondary neural tubes in the NSB. A, Schematic representations of the NSB at HH8 and HH10, indicating the approximate axial level of the sections shown in $\boldsymbol{B}-\boldsymbol{E}$. n, Hensen's node; $\mathrm{ps}$, primitive streak. $\boldsymbol{B}-\boldsymbol{E}$, (FSE visualization (left panels) and immunostainings for fibronectin (middle panels) and Sox-2 (right panels), all combined with DAPI staining, on cross-sections through the rostral $(\boldsymbol{B}, \boldsymbol{C})$ and caudal $(\boldsymbol{D}, \boldsymbol{E})$ parts of the NSB. Embryos were labeled at HH8 $(\boldsymbol{B}, \boldsymbol{D})$ and $H H 10(\boldsymbol{C}, \boldsymbol{E})$ with CFSE for $1 \mathrm{~h}$ and further incubated for $3 \mathrm{~h}$ before analysis. Arrows indicate the portion of the neural plate where ingression occurs. In the rostral NSB (B), ingression is limited to the midline, whereas in its caudal end (D), it extends up to the neural folds. As a consequence of the greater proportion of cells undergoing movements of primary neurulation, the size of the lumen (indicated by a double-headed arrow) at $H H 10$ is longer rostrally than caudally $(\boldsymbol{C}, \boldsymbol{E})$. e, Ectoderm; n, Hensen's node; nf, neural fold; nt, neural tissue; pm, paraxial mesoderm. Scale bar, $50 \mu \mathrm{m}$. $\boldsymbol{F}$, Schematic representations of the NSB at HH8 (left panel) and the resulting spinal cord (right panel), reconstituting the different populations that constitute the NSB at HH8 and their ultimate contribution to the neural tube along the rostrocaudal axis. Light blue represents Sox-2-positive neural cells executing movements of primary neurulation; blue dots indicate Sox-2-negative neural progenitors undergoing EMT; green represents notochord. n, Hensen's node; ps, primitive streak. 
A

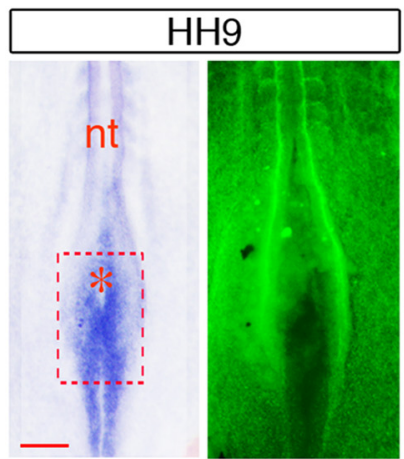

Prickle-1 Fibronectin

C

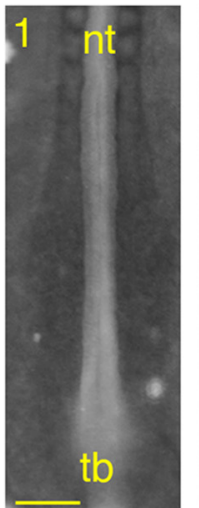

Control

$\mathrm{HH} 8$

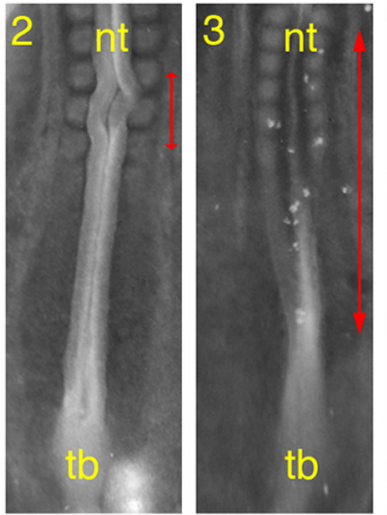

Prickle-1

$\mathrm{HH} 8$
$\mathrm{HH} 10$

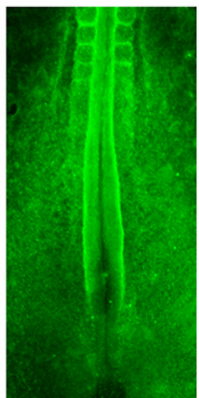

Fibronectin

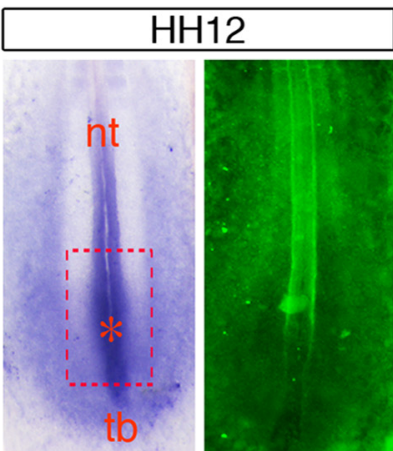

Prickle-1 Fibronectin
B

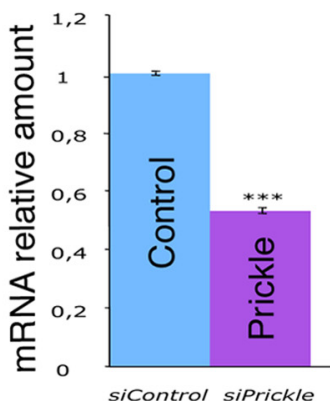

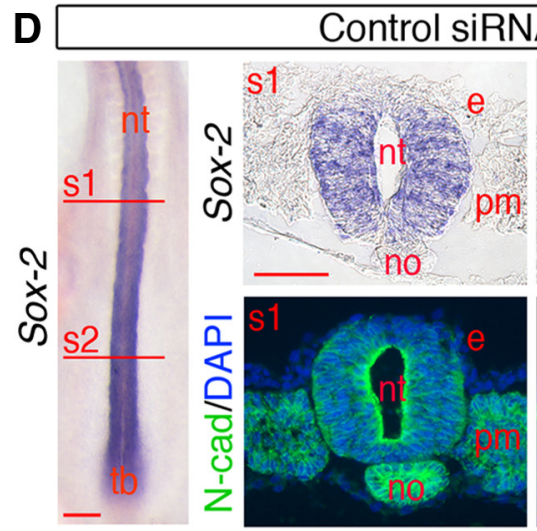

E

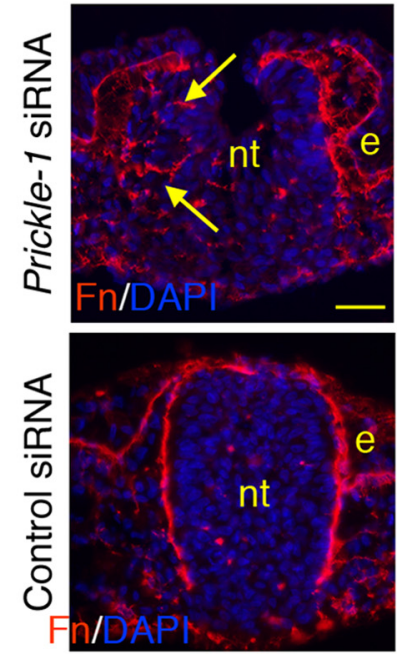

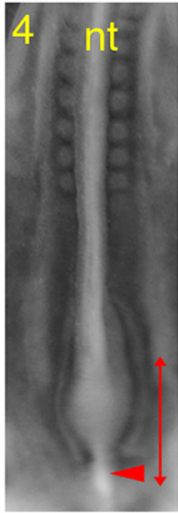

Prickle-1

$\mathrm{HH} 9$

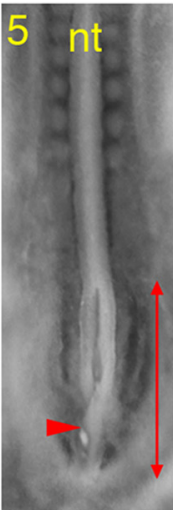

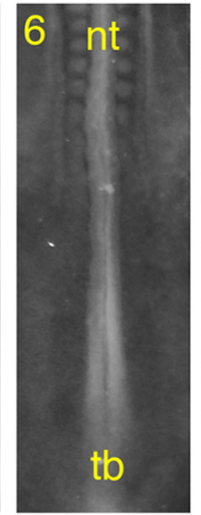

Prickle-1

$\mathrm{HH} 7 \mathrm{HH} 10$

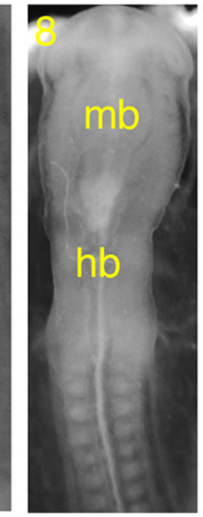

Prickle-1

PN

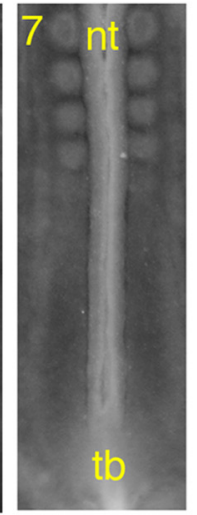


eral folds caudally (Fig. $6 A, B, D$ ). Consistently, at $\mathrm{HH} 10$, the vast majority of cells within the neural tube were labeled for CFSE rostrally while they were confined to the very dorsal aspect of the neural tube more caudally (Fig. 6A, C,E). Therefore, the more rostral the axial level in the junctional region, the larger the contribution to the neural tube of cells executing movements of elevation and folding (Fig. $6 F$ ). Conversely, the more caudal the axial level in the junctional region, the larger the participation to the neural tube of cells generated by EMT (Fig. $6 F$ ). Such a spatial organization of cells in the NSB is likely to ensure the topological continuity of the junctional neural tube with the primary one while supplying all neural progenitors of the caudal neural tube formed by secondary neurulation.

\section{Prickle-1 is required for the transition between primary and secondary neurulations}

We then searched for molecular players specifically expressed in the NSB that might account for the distinct neurulation process operating in the junction. Among the many candidate molecules identified in genetic studies in mouse and human (Copp et al., 2003, 2013; Copp and Greene, 2010; Harris and Juriloff, 2010), members of the planar cell polarity (PCP) pathway, including Famingo, Vangl-2, Scrib, and Prickle-1, have been found to play a critical role in neurulation (Ybot-Gonzalez et al., 2007). Interest-

\section{$\leftarrow$}

Figure 7. Prickle-1 knockdown in the NSB causes anomalies phenocopying lower spine NTDs in human. $\boldsymbol{A}$, Whole-mount in situ hybridizations for Prickle-1 in embryos and whole-mount immunostainings for fibronectin at $\mathrm{HH}$-HH12. Prickle- 1 is markedly expressed caudally both in the NSB and in the tail bud, and is fainter (if any detectable) rostrally. Its expression in the medial part of the NSB matches the gradual deposition of fibronectin along the neural tube. The red, dotted squares represent the initial position of the NSB at HH8; asterisks indicate the positions of the node. nt, Neural tube; tb, tail bud. Scale bar, $100 \mu \mathrm{m}$. B, Quantitative PCR quantitation of Prickle-1 messages in embryos treated with Prickle-1 and control siRNAs. ${ }^{* * *} p<0.001$. C, Bright-field views of the caudal part of chick embryos treated at the level of the NSB at defined stages between $\mathrm{HH} 7$ and $\mathrm{HH} 10$ with control (1) or Prickle-1 (3-7) siRNAs. (8, Bright-field view of the rostral part of an embryo treated with Prickle-1 siRNAs at the level of the primary neural tube (PN). Embryos were all at HH13-HH14 when collected $18 \mathrm{~h}$ after treatment. Embryos treated with Prickle-1 siRNAs at HH8-HH9 show severe NTDs in the caudal neural tube, ranging from extensive spina bifida $>10$ somites long to local spinal dysraphisms and malformations of the tail bud. Double-headed arrows indicate the regions where the neural tube is affected and the arrowheads point at abnormally thin tail buds. In contrast, control embryos or embryos treated with Prickle-1 siRNAs during primary neurulation, before (at $\mathrm{HH}$ ) or after (at HH10) neurulation movements in the NSB show no overt defaults. hb, Hindbrain; mb, midbrain; $n t$, neural tube; tb, tail bud. Scale bar, $200 \mu \mathrm{m}$. D, Histological characterization of the neural tube in embryos treated with control (left panels) or Prickle-1 (right panels) siRNAs at HH8. Whole-mount in situ hybridizations for Sox-2 showing a severe spinal dysraphism at the level of the caudal neural tube in the chick embryo treated with the Prickle- 1 siRNAs and not in the control. In situ hybridization for Sox-2 and immunostaining for $\mathrm{N}$-cadherin on cross-sections through the rostral (s1) and caudal (s2) regions of the affected regions of Prickle-1-siRNA-treated embryos exhibiting extensive spina bifida and the corresponding levels in the control-siRNA-treated specimens. Short arrows point to the abnormally distributed cells in the central portion of the neural tube. Scale bars, $100 \mu \mathrm{m}$. $\boldsymbol{E}$, Immunostaining for fibronectin and DAPI staining on cross-sections through the caudal part of a control embryo (bottom) and of an embryo presenting an abnormal tail bud (top), showing defects in polarized distribution of fibronectin along the neural tube (arrows) and aberrantly organized cells in its mid-part. e, Ectoderm; no, notochord; nt, neural tissue; pm, paraxial mesoderm. Scale bar, $50 \mu \mathrm{m} . \boldsymbol{F}, \mathbf{G}$ Anatomical and histological characterization of a thoracolumbar spinal dysraphisms in a human fetus. $\boldsymbol{F}$, Dorsal view of an 18 -week human fetus exhibiting a severe thoracolumbar spinal dysraphism. Double-headed arrows indicate the portions of the spinal cord within the affected region that present an open or a closed dysraphism. L, Lumbar vertebrae; $S$, sacral vertebrae; up.T, upper thoracic vertebrae; low.T, lower thoracic vertebrae. Scale bar, $2.5 \mathrm{~mm}$. G, Histological sections stained with trichrome blue through the affected region at the lower-thoracic and lumbar levels of the fetus shown in $\boldsymbol{F}$, illustrating the dual defects of the spinal cord. At both levels, the skin consists only of a thin epithelial layer devoid of dermis. The arrow points to the truncated dorsal aspect of the lumbar spinal cord infiltrated by blood vessels. spc, Spinal cord; vrtb, vertebra. Scale bar, $500 \mu \mathrm{m}$. ingly, whereas mutations in the Flamingo, Vangl-2, and Scrib genes invariably lead to craniorachischisis in mouse and to severe types of NTDs extending over long portions of the neural axis in human, mutations in Prickle-1 in human were found to generate only local spinal dysraphisms (Bosoi et al., 2011; Copp et al., 2013; Cai and Shi, 2014). Therefore, we examined the expression profile of Prickle-1 during neurulation in chick embryos. Interestingly, consistent with a previous report (Cooper et al., 2008), Prickle- 1 was prominent in the NSB and in the elongating caudal neural tube and was almost absent from the primary neural tube (Fig. 7A), suggesting a specific role during the transition between neurulations.

To define the role of Prickle- 1 in neurulation at the junction, we performed loss-of-function experiments using RNAi knockdown. To this aim, Prickle-1 siRNAs were applied to the NSB by lipofection, allowing their massive and fast delivery specifically to neural progenitors situated superficially. When applied at HH8-9, control siRNAs were ineffective in most cases and produced minor morphological alterations in only a few embryos ( $n=2$ of 19; Fig. 7C1), whereas Prickle-1 siRNAs reduced its expression by $50 \%$ within $6 \mathrm{~h}$ (Fig. $7 \mathrm{~B}$ ) and provoked a variety of caudal defects ( $n=18$ of 20; Fig. 7C2-C5). A significant proportion of the embryos presented NTDs either locally (12 of 20; Fig. $7 C 2$ ) or extending over a large portion of the trunk (6 of 20; Fig. 7C3). Treatment at $\mathrm{HH} 9$ also produced axial defects, but these were generally situated more caudally and often associated with reduced tail buds ( 9 of 10; Fig. 7C4-C5). Histological analyses of the affected regions of embryos with extended NTDs revealed a wide-opened neural tube rostrally, whereas more caudally, it was organized as two poorly connected structures: one dorsally with a neural-plate aspect and one ventrally consisting of a mass of disorganized cells, and no lumen could be distinguished (Fig. 7D). Control embryos, in contrast, displayed fully closed neural tubes with recognizable lumens, both anteriorly and posteriorly (Fig. 7D). Prickle-1 siRNAs, in contrast, did not produce overt damage to the neural tube when applied before (at HH7) or after (at HH10) movements of intercalation and accretion $(n=14$ of 15; Fig. 7C6-C7) or during primary neurulation ( $n=8$ of 8 ; Fig. $7 C 8)$, consistent with its restricted spatiotemporal expression in the caudal neural tube.

Prickle-1 has been shown to regulate polarized deposition of fibronectin on the surface of cells undergoing movements of convergence extension during Xenopus and mouse gastrulation (Goto et al., 2005; Dzamba et al., 2009; Tao et al., 2009). Interestingly, we found that, in the NSB, fibronectin deposition in the basement membrane along the neural tube matched Prickle-1 expression (Fig. 7A) and that embryos treated with Prickle-1 siRNAs displayed nonpolarized expression of fibronectin in the caudal neural tube, contrary to control siRNA-treated embryos in which fibronectin was distributed in a well-defined basement membrane delineating the neural tube outline (Fig. 7E). This suggests that the lack of an organized basement membrane along mesenchymal neural progenitors perturbs their regroupment into an epithelium, resulting in the absence of coupling between dorsal and ventral cell populations and also disrupting tail bud organization.

\section{Morphological and histological characterization of a human fetus presenting a severe spinal dysraphism in its thoracolumbar region}

To determine whether our data on chick embryo may be transposed to humans and thus provide a molecular and cellular basis for understanding the causality of NTD prevalence in patients, we 
analyzed an 18-week human fetus exhibiting a severe spinal dysraphism in its thoracolumbar region. Strikingly, its affected spinal cord divided into two contiguous domains: one rostrally, which presented all features of an open NTD, with incomplete vertebrae and a wide-open spinal cord exposed to the exterior and in continuity with the epidermis; and one caudally, which resembled some closed NTDs, with a rod-shaped, truncated spinal cord lacking a central canal and covered with a thin, transparent skin devoid of dermis (Fig. $7 F, G$ ). These defects reflect in every respect the malformations induced by the Prickle-1 siRNAs in the chicken (compare with Fig. $7 C, D$ ) and suggest that similar morphogenetic events are involved in the shaping of the lower neural tube in humans.

\section{Discussion}

Previous fate-mapping studies in chick and mouse established that all neural progenitors of the caudal half of the spinal cord derive from the NSB (Catala et al., 1996; Cambray and Wilson, 2002; Shimokita and Takahashi, 2011). Using the chick model, our study explains, for the first time, how these neural progenitors are produced here, released, displaced, and reassembled to form the ventral part of the junctional neural tube as well as the entire secondary neural tube. Although it is often assimilated to the rostral portion of the streak, the NSB is arguably a discrete zone specifically devoted to the transition between primary and secondary neurulations. It is composed rostrolaterally of a cell population giving rise to the dorsal neural tube and in topological continuity with the primary neural tube, and it shares with it several features, notably elevating and fusing neural folds separated by a neural groove. These features are gradually less pronounced caudally, with only reduced folds and a short neural groove in its very caudal aspect (e.g., see Fig. 6). Conversely, the NSB contains medial cells that later form the ventral neural tube and undergo an ingression phenomenon involving an EMT that has not been described previously. In an opposite gradient to the lateral population, the proportion of cells executing EMT increases caudally in proximity to the primitive streak. Thus, the neural tube forms along the rostrocaudal axis by at least three different mechanisms involving distinct morphogenetic movements, thereby accounting for the diversity of the phenotypes observed among NTDs. Yet, beyond this apparent diversity, there appears a remarkable unity and continuity between the different modes of neurulation. Indeed, our CFSE-tracing experiments confirm previous studies suggesting that, at all axial levels, the precursors of the neural tube are initially always located in the superficial layer, centered around the node throughout the course of its regression (Catala et al., 1996; Cambray and Wilson, 2002; Shimokita and Takahashi, 2011). This might explain why disorders affecting the lower spine may sometimes generate defects characterized by an open neural plate as in the head (Copp et al., 2013).

The question remains, however, as to whether, in the NSB, cells are committed neural progenitors or constitute a population of "stem" cells. Indeed, clonal lineage analyses in chick and mouse revealed the existence in this region of progenitors with stem cell properties capable of giving rise to both neural and mesodermal descendants, although the extent of their actual participation to the final tissues remains to be established (Wilson et al., 2009). Our data based on CFSE tracing show that surface NSB cells do not contribute to mesoderm, indicating that, at $\mathrm{HH} 8$, they are already engaged in the neural lineage. This does not exclude, however, that this population may contain a number of progenitors that maintain over time properties of stem cells that can be recruited under particular experimental conditions to adopt epidermal, neural, or mesodermal fates. Surprisingly, at least some of these precursors (i.e., those situated medially) do not express Sox-2. Previous studies revealed that one of the Sox2-enhancers regulating its expression, enhancer $\mathrm{N} 1$, is activated in the NSB at onset of neurulation under the control of the synergistic actions of Wnt and FGF signals, but that its activation does not immediately lead to Sox-2 expression in cells due to local repression by BMP signaling (Takemoto et al., 2006, , 2011). Interestingly, in a striking parallel with our observations, it has been found that, during gastrulation, cell decision either to remain in the superficial layer and to give rise to the neurectoderm or to ingress into the primitive streak and to become mesoderm is determined by the balance between the mutually repressing Snail-2 and Sox-2/3 transcription factors (Acloque et al., 2011). Therefore, we propose that cells situated medially in the NSB are committed precociously into neural progenitors. However, because of persistent BMP-4 signaling, these progenitors express Snail-2, which in turn represses Sox-2, allowing them to undergo EMT and occupy the underlying space. Upon cessation of BMP activity, these cells do not maintain Snail-2 expression and turn on Sox-2, possibly inducing their subsequent reincorporation into the neural tube anlage.

In an assessment of molecular players involved in junctional neurulation, we found that Prickle-1, a member of the PCP pathway, is recruited to the NSB and that its misexpression in the junctional area causes severe NTDs in the caudal half of chick embryos. As a member of the PCP signaling pathway, Prickle- 1 is thought to participate to the movements of convergence-extension occurring during neurulation throughout the neural axis (Ybot-Gonzalez et al., 2007). However, its restricted distribution in the NSB and in the caudal neural tube and not during primary neurulation rather suggests that it may play alternative roles during neurulation. Interestingly, several studies in the Xenopus embryo as well as the analysis of null mouse embryos uncovered a role of Prickle- 1 in the maintenance of apicobasal polarity, in the polarized deposition of extracellular matrix components in a basement membrane, and in the control of mitotic spindle orientation (Goto et al., 2005; Dzamba et al., 2009; Tao et al., 2009). Thus, our finding that, in the knocked-down embryos, neural progenitors in the NSB and in the tail bud fail to organize a proper basement membrane at their basal side suggests that Prickle- 1 is merely involved in promoting cell polarity among cells rather than in movements of convergence-extension.

It is striking that specific inhibition of Prickle-1 expression in the NSB during a defined time window caused anomalies recapitulating precisely, both in their anatomical location and histological features, those found in a human fetus with a severe thoracolumbar spinal dysraphism (Fig. 7). Interestingly, a great proportion of the previously reported cases of human embryos with lower spine NTDs also exhibited striking morphological discontinuities between the rostral and caudal parts of the spinal cord (Lemire et al., 1965; Saitsu et al., 2007), thus raising the intriguing possibility that spinal dysraphisms may result essentially from deficient connections between the primary and secondary neural tubes. This adds to the list of possible developmental defects causing NTDs and may account for the cases that received thus far no satisfactory explanation with the current models. Indeed, failure in the formation of initiation sites of neural tube closure or in the posterior neuropore closure has been put forward as a major cause of NTDs (Copp, 2005). However, although these events might be responsible for anencephalies, craniorachischisis, or cases of cystic dilatation of the neural tube 
(Ikenouchi et al., 2002; Copp, 2005), they cannot explain simply the location and morphological characteristics of lower spine NTDs. Whether these human embryos and fetuses presented mutations in PRICKLE1 gene has unfortunately not been determined. However, numerous heterozygous mutations were found in genes of the PCP signaling pathway among patients suffering NTDs (Kibar et al., 2007; Bosoi et al., 2011; Robinson et al., 2012; Wu et al., 2011; Juriloff and Harris, 2012; Cai and Shi, 2014). Some mutations are associated as in mice with craniorachioschisis, whereas others (notably PRICKLE1) are seen only in cases of spina bifida. Our results therefore reinforce the hypothesis of a crucial role played by PRICKLE1 in the control of human neurulation specifically in the lower spinal cord.

In conclusion, our data uncover another mechanism of neural tube closure at a region frequently associated with NTD and emphasize its anatomical importance along the rostrocaudal axis. Because the morphogenetic events deployed are unique, we propose the term "junctional neurulation" to name the whole process. In addition, because of the great similarities in the phenotypes of Prickle-1-knocked-down chick embryos and of human embryos and fetuses with spinal dysraphisms, our study may provide molecular and cellular bases for elucidating the strong prevalence of NTDs in the lower spine in human and illustrates the importance of both spatial and temporal aspects in their occurrence, thereby accounting for the strong heterogeneity of their forms. Recently, Copp et al. (2013) raised questions on the functional implications of missense mutations in humans. The use of chick embryos is in our view an excellent system to test the effect of these mutant proteins.

\section{References}

Acloque H, Ocaña OH, Matheu A, Rizzoti K, Wise C, Lovell-Badge R, Nieto MA (2011) Reciprocal repression between Sox 3 and snail transcription factors defines embryonic territories at gastrulation. Dev Cell 21:546558. CrossRef Medline

Bollérot K, Sugiyama D, Escriou V, Gautier R, Tozer S, Scherman D, Jaffredo $\mathrm{T}$ (2006) Widespread lipoplex-mediated gene transfer to vascular endothelial cells and hemangioblasts in the vertebrate embryo. Dev Dyn 235: 105-114. CrossRef Medline

Bosoi CM, Capra V, Allache R, Trinh VQ, De Marco P, Merello E, Drapeau P, Bassuk AG, Kibar Z (2011) Identification and characterization of novel rare mutations in the planar cell polarity gene PRICKLE1 in human neural tube defects. Hum Mutat 32:1371-1375. CrossRef Medline

Cai C, Shi O (2014) Genetic evidence in planar cell polarity signaling pathway in human neural tube defects. Front Med 8:68-78. CrossRef Medline

Cambray N, Wilson V (2002) Axial progenitors with extensive potency are localised to the mouse chordoneural hinge. Development 129:48554866. Medline

Catala M, Teillet MA, Le Douarin NM (1995) Organization and development of the tail bud analyzed with the quail-chick chimaera system. Mech Dev 51:51-65. CrossRef Medline

Catala M, Teillet MA, De Robertis EM, Le Douarin ML (1996) A spinal cord fate map in the avian embryo: while regressing, Hensen's node lays down the notochord and floor plate thus joining the spinal cord lateral walls. Development 122:2599-2610. Medline

Chapman SC, Collignon J, Schoenwolf GC, Lumsden A (2001) Improved method for chick whole-embryo culture using a filter paper carrier. Dev Dyn 220:284-289. CrossRef Medline

Colas JF, Schoenwolf GC (2001) Towards a cellular and molecular understanding of neurulation. Dev Dyn 221:117-145. CrossRef Medline

Cooper O, Sweetman D, Wagstaff L, Münsterberg A (2008) Expression of avian prickle genes during early development and organogenesis. Dev Dyn 237:1442-1448. CrossRef Medline

Copp AJ (2005) Neurulation in the cranial region: normal and abnormal. J Anat 207:623-635. CrossRef Medline

Copp AJ, Greene ND (2010) Genetics and development of neural tube defects. J Pathol 220:217-230. CrossRef Medline
Copp AJ, Greene ND, Murdoch JN (2003) The genetic basis of mammalian neurulation. Nat Rev Genet 4:784-793. CrossRef Medline

Copp AJ, Stanier P, Greene ND (2013) Neural tube defects: recent advances, unsolved questions, and controversies. Lancet Neurol 12:799-810. CrossRef Medline

Criley BB (1969) Analysis of embryonic sources and mechanisms of development of posterior levels of chick neural tubes. J Morphol 128:465-501. CrossRef Medline

Dady A, Blavet C, Duband JL (2012) Timing and kinetics of E- to $\mathrm{N}$-cadherin switch during neurulation in the avian embryo. Dev Dyn 241:1333-1349. CrossRef Medline

De Marco P, Merello E, Mascelli S, Capra V (2006) Current perspectives on the genetic causes of neural tube defects. Neurogenetics 7:201-221. CrossRef Medline

Dzamba BJ, Jakab KR, Marsden M, Schwartz MA, DeSimone DW (2009) Cadherin adhesion, tissue tension, and noncanonical Wnt signaling regulate fibronectin matrix organization. Dev Cell 16:421-432. CrossRef Medline

Goto T, Davidson L, Asashima M, Keller R (2005) Planar cell polarity genes regulate polarized extracellular matrix deposition during frog gastrulation. Curr Biol 15:787-793. CrossRef Medline

Hamburger V, Hamilton HL (1951) A series of normal stages in the development of the chick embryo. J Morphol 88:49-92. CrossRef Medline

Harris MJ, Juriloff DM (2007) Mouse mutants with neural tube closure defects and their role in understanding human neural tube defects. Birth Defects Res A Clin Mol Teratol 79:187-210. CrossRef Medline

Harris MJ, Juriloff DM (2010) An update to the list of mouse mutants with neural tube closure defects and advances toward a complete genetic perspective of neural tube closure. Birth Defects Res A Clin Mol Teratol 88:653-669. CrossRef Medline

Hughes AF, Freeman RB (1974) Comparative remarks on the development of the tail cord among higher vertebrates. J Embryol Exp Morphol 32: 355-363. Medline

Ikenouchi J, Uwabe C, Nakatsu T, Hirose M, Shiota K (2002) Embryonic hydromyelia: cystic dilatation of the lumbosacral neural tube in human embryos. Acta Neuropathol 103:248-254. CrossRef Medline

Juriloff DM, Harris MJ (2012) A consideration of the evidence that genetic defects in planar cell polarity contribute to the etiology of human neural tube defects. Birth Defects Res A Clin Mol Teratol 94:824-840. CrossRef Medline

Kibar Z, Torban E, McDearmid JR, Reynolds A, Berghout J, Mathieu M, Kirillova I, De Marco P, Merello E, Hayes JM, Wallingford JB, Drapeau P, Capra V, Gros P (2007) Mutations in VANGL1 associated with neuraltube defects. N Engl J Med 356:1432-1437. CrossRef Medline

Kimura W, Yasugi S, Stern CD, Fukuda K (2006) Fate and plasticity of the endoderm in the early chick embryo. Dev Biol 289:283-295. CrossRef Medline

Lemire RJ, Shepard TH, Alvord EC Jr (1965) Caudal myeloschisis (lumbosacral spina bifida cystica) in a five millimeter (horizon Xiv) human embryo. Anat Rec 152:9-16. CrossRef Medline

Lowery LA, Sive H (2004) Strategies of vertebrate neurulation and a reevaluation of teleost neural tube formation. Mech Dev 121:1189-1197. CrossRef Medline

Nakaya Y, Kuroda S, Katagiri YT, Kaibuchi K, Takahashi Y (2004) Mesenchymal-epithelial transition during somitic segmentation is regulated by differential roles of Cdc42 and Rac1. Dev Cell 7:425-438. CrossRef Medline

Nievelstein RA, Hartwig NG, Vermeij-Keers C, Valk J (1993) Embryonic development of the mammalian caudal neural tube. Teratology 48:21-31. CrossRef Medline

O'Rahilly R, Muller F (2003) Somites, spinal ganglia, and centra: enumeration and interrelationships in staged human embryos, and implications for neural tube defects. Cells Tiss Org 173:75-92. CrossRef Medline

O’Rahilly R, Müller F (1994) Neurulation in the normal human embryo. Ciba Found Symp 181:70-82; discussion 82-89. Medline

Robinson A, Escuin S, Doudney K, Vekemans M, Stevenson RE, Greene ND, Copp AJ, Stanier P (2011) Mutations in the planar cell polarity genes CELSR1 and SCRIB are associated with the severe neural tube defect craniorachischisis. Hum Mutat 33:440-447. CrossRef Medline

Rovasio RA, Delouvée A, Yamada KM, Timpl R, Thiery JP (1983) Neural crest cell migration: requirements for exogenous fibronectin and high cell density. J Cell Biol 96:462-473. CrossRef Medline 
Saitsu H, Yamada S, Uwabe C, Ishibashi M, Shiota K (2004) Development of the posterior neural tube in human embryos. Anat Embryol 209:107-117. CrossRef Medline

Saitsu H, Yamada S, Uwabe C, Ishibashi M, Shiota K (2007) Aberrant differentiation of the axially condensed tail bud mesenchyme in human embryos with lumbosacral myeloschisis. Anat Rec 290:251-258. CrossRef Medline

Schlegel A, Largeau C, Bigey P, Bessodes M, Lebozec K, Scherman D, Escriou V (2011) Anionic polymers for decreased toxicity and enhanced in vivo delivery of siRNA complexed with cationic liposomes. J Control Release 152:393-401. CrossRef Medline

Schoenwolf GC (1979) Histological and ultrastructural observations of tail bud formation in the chick embryo. Anat Rec 193:131-147. CrossRef Medline

Schoenwolf GC (1984) Histological and ultrastructural studies of secondary neurulation in mouse embryos. Am J Anat 169:361-376. CrossRef Medline

Schoenwolf GC, Delongo J (1980) Ultrastructure of secondary neurulation in the chick embryo. Am J Anat 158:43-63. CrossRef Medline

Shimokita E, Takahashi Y (2011) Secondary neurulation: fate-mapping and gene manipulation of the neural tube in tail bud. Dev Growth Differ 53:401-410. CrossRef Medline

Shum AS, Tang LS, Copp AJ, Roelink H (2010) Lack of motor neuron differentiation is an intrinsic property of the mouse secondary neural tube. Dev Dyn 239:3192-3203. CrossRef Medline

Takemoto T, Uchikawa M, Kamachi Y, Kondoh H (2006) Convergence of Wnt and FGF signals in the genesis of posterior neural plate through activation of the Sox2 enhancer N-1. Development 133:297-306. CrossRef Medline

Takemoto T, Uchikawa M, Yoshida M, Bell DM, Lovell-Badge R, Papaioannou VE, Kondoh H (2011) Tbx6-dependent Sox2 regulation deter- mines neural or mesodermal fate in axial stem cells. Nature 470:394-398. CrossRef Medline

Tao H, Suzuki M, Kiyonari H, Abe T, Sasaoka T, Ueno N (2009) Mouse prickle1, the homolog of a PCP gene, is essential for epiblast apical-basal polarity. Proc Natl Acad Sci U S A 106:14426-14431. CrossRef Medline

Thiery JP, Sleeman JP (2006) Complex networks orchestrate epithelialmesenchymal transitions. Nat Rev Mol Cell Biol 7:131-142. CrossRef Medline

Tortori-Donati P, Rossi A, Cama A (2000) Spinal dysraphism: a review of neuroradiological features with embryological correlations and proposal for a new classification. Neuroradiology 42:471-491. CrossRef Medline

Wallingford JB, Niswander LA, Shaw GM, Finnell RH (2013) The continuing challenge of understanding, preventing, and treating neural tube defects. Science 339:1222002. CrossRef Medline

Welch K, Winston KR (1987) Spina bifida. In: Handbook of clinical neurology, Vol. 6: Malformations (Myrianthopoulos NC, ed). New York: Elsevier Science.

Wiegreffe C, Christ B, Huang R, Scaal M (2009) Remodeling of aortic smooth muscle during avian embryonic development. Dev Dyn 238:624631. CrossRef Medline

Wilson V, Olivera-Martinez I, Storey KG (2009) Stem cells, signals and vertebrate body axis extension. Development 136:1591-1604. CrossRef Medline

Wu G, Huang X, Hua Y, Mu D (2011) Roles of planar cell polarity pathways in the development of neural [correction of neutral] tube defects. J Biomed Sci 18:66. CrossRef Medline

Ybot-Gonzalez P, Savery D, Gerrelli D, Signore M, Mitchell CE, Faux CH, Greene ND, Copp AJ (2007) Convergent extension, planar-cell-polarity signalling and initiation of mouse neural tube closure. Development 134: 789-799. CrossRef Medline 